\title{
Functional Mapping of Face-Selective Regions in the Extrastriate Visual Cortex of the Marmoset
}

\author{
[DChia-Chun Hung, ${ }^{1,2}$ Cecil C. Yen, ${ }^{1}$ Jennifer L. Ciuchta, ${ }^{1}$ Daniel Papoti, ${ }^{1}$ Nicholas A. Bock, ${ }^{3}$ David A. Leopold, ${ }^{2,4}$ \\ and ${ }^{\circ}$ Afonso C. Silva ${ }^{1}$ \\ ${ }^{1}$ Cerebral Microcirculation Section, Laboratory of Functional and Molecular Imaging, National Institute of Neurological Disorders and Stroke, National \\ Institutes of Health, Bethesda, Maryland 20892, ${ }^{2}$ Section on Cognitive Neurophysiology and Imaging, Laboratory of Neuropsychology, National Institute of \\ Mental Health, National Institutes of Health, Bethesda, Maryland 20892, ${ }^{3}$ Medical Physics and Applied Radiation Sciences, McMaster University, Hamilton, \\ Ontario L8S 4K1, Canada, and ${ }^{4}$ Neurophysiology Imaging Facility, National Institute of Mental Health, National Institute of Neurological Disorders and \\ Stroke, National Eye Institute, National Institutes of Health, Bethesda, Maryland 20182
}

The cerebral cortex of humans and macaques has specialized regions for processing faces and other visual stimulus categories. It is unknown whether a similar functional organization exists in New World monkeys, such as the common marmoset (Callithrix jacchus), a species of growing interest as a primate model in neuroscience. To address this question, we measured selective neural responses in the brain of four awake marmosets trained to fix their gaze upon images of faces, bodies, objects, and control patterns. In two of the subjects, we measured high gamma-range field potentials from electrocorticography arrays implanted over a large portion of the occipital and inferotemporal cortex. In the other two subjects, we measured BOLD fMRI responses across the entire brain. Both techniques revealed robust, regionally specific patterns of category-selective neural responses. We report that at least six face-selective patches mark the occipitotemporal pathway of the marmoset, with the most anterior patches showing the strongest preference for faces over other stimuli. The similar appearance of these patches to previous findings in macaques and humans, including their apparent arrangement in two parallel pathways, suggests that core elements of the face processing network were present in the common anthropoid primate ancestor living $\sim 35$ million years ago. The findings also identify the marmoset as a viable animal model system for studying specialized neural mechanisms related to high-level social visual perception in humans.

Key words: ECoG; evolution; face; fMRI; marmoset; visual cortex

\section{Introduction}

The cerebral cortex of humans and macaques is specialized for the visual processing of faces and other social stimuli, which likely reflects the fact that primates, unlike most mammals, depend primarily on vision for social signaling (Leopold and Rhodes, 2010). Evidence for such specialization comes largely from fMRI experiments, which have identified cortical regions in both humans and macaques that respond more strongly to faces than to other structured objects. In humans, faces selectively activate the mid fusiform gyrus (Kanwisher et al., 1997), the lateral occipital

Received June 27, 2014; revised Nov. 12, 2014; accepted Nov. 18, 2014.

Author contributions: C.-C.H., C.C.Y., D.A.L., and A.C.S. designed research; C.-C.H., C.C.Y., and J.L.C. performed research; D.P. and N.A.B. contributed unpublished reagents/analytic tools; C.-C.H., C.C.Y., J.L.C., N.A.B., D.A.L., and A.C.S. analyzed data; C.-C.H., C.C.Y., D.A.L., and A.C.S. wrote the paper.

This work was supported by the Intramural Research Programs of the National Institute of Neurological Disorders and Stroke and National Institute of Mental Health. We thank Dr. R. Saunders for implanting the ECOG arrays in two animals; J. Day Cooney, L. Zhang, J. Mackel, T. Talbot, and R. Villadiego for technical assistance; and Dr. R. Berman for comments on the manuscript.

The authors declare no competing financial interests.

Correspondence should be addressed to Dr. Afonso C. Silva, Cerebral Microcirculation Section, Laboratory of Functional and Molecular Imaging, National Institute of Neurological Disorders and Stroke, National Institutes of Health, 49 Convent Drive, MSC 1065, Building 49, Room 3A72, Bethesda, MD 20892-1065. E-mail: SilvaA@ninds.nih.gov.

DOI:10.1523/JNEUROSCI.2659-14.2015

Copyright $\odot 2015$ the authors $\quad 0270-6474 / 15 / 351160-13 \$ 15.00 / 0$ cortex (Puce et al., 1996), the anterior and posterior regions of the superior temporal sulcus (Puce et al., 1998; Pitcher et al., 2011), and the anterior portion of the inferotemporal cortex (Kriegeskorte et al., 2007). In macaques, a similar diversity of face "patches" exists in the ventral visual stream, particularly in and around the superior temporal sulcus (Tsao et al., 2003; Pinsk et al., 2005; Bell et al., 2009; Ku et al., 2011). Electrophysiological studies performed both in macaques (Tsao et al., 2006; Gross, 2008; Tsao and Livingstone, 2008) and in humans (Bentin et al., 1996; Parvizi et al., 2012) revealed that these patches contain a functional clustering of neurons that respond selectively to the visual presentation of faces. Establishing a more precise correspondence between face patches in the two species is an active area of research (Tsao et al., 2008; Ku et al., 2011; Yovel and Freiwald, 2013).

The evolutionary origins of face networks in the brain are not well understood, in part because comparative data are limited. Among primates, face-selective responses have been measured only in macaques and humans, with few exceptions (Zangenehpour and Chaudhuri, 2005; Parr et al., 2009). Outside of primates, only one other species, the sheep, has been tested for such responses. Electrophysiological recordings from neurons in the sheep's temporal cortex revealed selective responses to faces of both sheep and humans, although the spatial organization of 
Table 1. Performance and fixation patterns of Marmoset $E^{a}$

\begin{tabular}{|c|c|c|c|c|c|c|}
\hline & Faces & Body parts & Objects & Spatial scramble & Phase scramble & Fixation dot alone \\
\hline No. of blocks attempted & 213 & 219 & 216 & 185 & 227 & 226 \\
\hline No. of valid blocks ( $>80 \%$ valid eye signal) & 204 & 205 & 200 & 152 & 187 & 175 \\
\hline$\%$ of valid blocks & 95.8 & 93.6 & 92.6 & 82.2 & 82.4 & 77.4 \\
\hline No. of fixations per block (mean $\pm S D$ ) & $29.42 \pm 7.42$ & $33.06 \pm 8.23$ & $31.77 \pm 8.26$ & $26.84 \pm 7.71$ & $28.42 \pm 7.79$ & $26.58 \pm 7.80$ \\
\hline Saccade amplitude $\left(^{\circ}\right)($ mean \pm SD) & $1.29 \pm 1.39$ & $1.47 \pm 1.41$ & $1.47 \pm 1.38$ & $1.70 \pm 1.65$ & $1.62 \pm 1.53$ & $1.77 \pm 1.65$ \\
\hline
\end{tabular}

${ }^{a}$ Behavioral performance and fixation patterns during the six different block types: face, body, object, spatial scramble, phase scramble, and fixation point alone of Marmoset $E$. The animal performed well in all six stimulus conditions (all $>75 \%$ ) with best performance in the three intact stimulus conditions ( $>90 \%)$.

Table 2. Performance and fixation patterns of Marmoset $B^{a}$

\begin{tabular}{|c|c|c|c|c|c|c|}
\hline & Faces & Body parts & Objects & Spatial scramble & Phase scramble & Fixation dot alone \\
\hline No. of blocks attempted & 164 & 183 & 184 & 183 & 180 & 185 \\
\hline No. of valid blocks (>80\% valid eye signal) & 160 & 180 & 173 & 163 & 171 & 139 \\
\hline$\%$ of valid blocks & 97.6 & 98.4 & 94.0 & 89.1 & 95.0 & 75.1 \\
\hline No. of fixations per block (mean \pm SD) & $36.18 \pm 6.29$ & $36.01 \pm 6.55$ & $33.84 \pm 6.65$ & $33.49 \pm 6.36$ & $34.42 \pm 6.84$ & $29.74 \pm 6.60$ \\
\hline Saccade amplitude $\left(^{\circ}\right)($ mean \pm SD) & $0.80 \pm 0.84$ & $1.24 \pm 1.22$ & $1.22 \pm 1.23$ & $1.34 \pm 1.33$ & $1.35 \pm 1.33$ & $1.77 \pm 1.89$ \\
\hline
\end{tabular}

${ }^{a}$ Behavioral performance and fixation patterns of Marmoset B in the fMRI experiment. Similar to Marmoset E, the performance was higher for blocks with structured images. All conventions are as in Table 1.

such responses across the cortex was not studied in detail (Kendrick and Baldwin, 1987).

The common marmoset (Callithrix jacchus) is a New World monkey of growing interest as an experimental model for systems neuroscience (Okano et al., 2012; Kishi et al., 2014; Solomon and Rosa, 2014). The organization of retinotopic cortical areas and their basic homology to areas in the macaque are well established (Rosa and Tweedale, 2005). However, to date, no study has investigated patterns of visual selectivity for faces or other complex objects in the marmoset or any New World primate species. Whether face-selective regions exist and how they are organized are important questions for at least two reasons. First, such information may shed light on the evolution of face processing and the homological relationships between face patches in macaques and humans. Second, if a similar network of face patches exists in the marmoset, researchers can use this species to study aspects of high-level social visual perception, taking advantage of its lissencephalic brain for electrophysiology (Mitchell et al., 2014), fMRI (Liu et al., 2013), and optical imaging experiments.

\section{Materials and Methods}

Subjects. Four healthy adult male common marmosets (C. jacchus) were used in this study: two were used in the electrocorticography (ECoG) experiments, whereas the other two were used in the fMRI experiments. All experiments were approved by the Animal Care and Use Committee of the National Institute of Neurological Disorders and Stroke.

Implantation of ECoG arrays. Each of the two marmosets was implanted with two 32 channel micro-ECoG arrays (NeuroNexus) in the right hemisphere. During surgery, the animals were positioned in a stereotaxic holder and ventilated with a mixture of air/oxygen and isoflurane anesthesia (1.5\%-2\%). Implantation of the ECoG arrays involved the removal of a bone flap $(\sim 1.2 \mathrm{~cm}$ in length $)$ over the occipitotemporal cortex. The anti-inflammatory corticosteroid dexamethasone $(2 \mathrm{mg} / \mathrm{ml}$, $0.04 \mathrm{ml}$ ) was administered intramuscularly before and after the surgery, and $3 \mathrm{ml}$ of $20 \%$ mannitol solution was given intravenously during the surgery, to prevent brain swelling. The position of the arrays was determined relative to the opening of the lateral sulcus, which was visible through the dura mater. For each array, a slit was made in the dura, and the array was advanced through the slit to its end position. After positioning the electrodes, the connectors were attached to the bone using dental acrylic and the reference and ground wires were placed over the dura through a burr hole in the opposite side of the skull. The bone flap was then sutured back in place. In the same surgery, a low profile threaded polyethel ether ketone headpost base was implanted over the frontal region and held in place by nylon screws (size $0-80 \times 3 / 32$ ",
Plastics One) and dental acrylic. The animals were given antibiotics and analgesics daily for $5 \mathrm{~d}$ after surgery. Following the animals' recovery, the position of each ECoG electrode in the arrays was precisely determined based on a high-resolution ( $0.15 \mathrm{~mm}$ isotropic) $\mathrm{T}_{2}$-weighted anatomical scan. This determination was facilitated by the growth of tissue through small windows in the electrode array, which was visible as a regular matrix of small bright dots in the image. The electrodes were placed in slightly different positions in the two animals and together covered the ventral visual pathway from $-10 \mathrm{~mm}$ to $+5 \mathrm{~mm}$ from the interaural line in the posteroanterior direction with $1 \mathrm{~mm}$ interelectrode distance.

Behavioral training. Animals were gradually acclimated to body and head restraint in the sphinx position (see Fig. $1 A$ ) over a period of 3 weeks (Silva et al., 2011). For both ECoG and fMRI testing, animals wore a jacket that permitted stabilization to the testing cradle. After the head was fixed, testing began with an eye calibration procedure. As the techniques for fixation and video-based eye movement recording differed slightly between the ECoG and fMRI settings, these are described in more detail below. For eye calibration, the animals directed their gaze to a sequence of small dots ( $1^{\circ}$ of visual angle) presented randomly at five different positions on the screen. Once the eyes were calibrated, testing began as described in the subsections below. During the experiments, the animals were rewarded with a drop of a sugary liquid reward $(\sim 0.01-$ $0.02 \mathrm{ml}$ ) for maintaining gaze within a $5^{\circ}$ radius window of the center of the screen. Hereafter, we use the term "fixation" to refer to the periods when gaze in this relatively large window is maintained. The integration of stimulus presentation, reward delivery, and eye tracking was controlled by MonkeyLogic software (Asaad et al., 2013).

Visual stimuli. We used five different image stimulus categories: conspecific faces, conspecific body parts, manmade objects, and two types of unstructured controls (see Fig. 1B). Both types of controls consisted of scrambled versions of the face stimuli. In the spatially scrambled version, control images were generated by first dividing the face images into $15 \times$ 25 square tiles and then randomly shuffling the position of the tiles. In the phase-scrambled version, control images were created by permuting the phase information while preserving the amplitude information of the spectrum of the face images. All images were first histogram equalized to increase the image contrast. To minimize luminance differences across the stimulus categories, we then normalized all the images to match the total intensity to one of the face images, selected arbitrarily. Twenty exemplars from each of the five categories were used in both the fMRI and ECoG experiments. For ECoG experiments, the stimuli subtended $5^{\circ}, 7^{\circ}$, or $10^{\circ}$. For the analysis described here, we observed no clear differences with stimulus size. Given the absence of stimulus size effects, we combined data from all image sizes for analyses described below. For the main $\mathrm{fMRI}$ experiments, the stimuli subtended $5^{\circ}$ visual angle. We also 
conducted additional control fMRI experiments in which we varied the stimulus size between $3^{\circ}$ and $7^{\circ}$.

ECoG testing procedures. For ECoG testing, the animals' heads were restrained using chronically implanted headposts. The implanted ECoG electrodes were connected to a BrainAmp amplifier (Brain Products) for data recording. Local field potentials were sampled at $1000 \mathrm{~Hz}$. Eye position was tracked using the EyeLink II video-based tracking (SR Research). Single images of faces, bodies, objects, and control patterns were presented briefly $(350,500$, or $650 \mathrm{~ms})$, with presentations separated by blank periods of variable duration $(350,500$, or $650 \mathrm{~ms})$. Stimuli from each of the five categories were randomly interleaved during blocks of trials consisting of 12-22 stimulus presentations. The marmoset received reward each time it successfully maintained fixation for two consecutive stimulus presentations. Trials in which the marmoset failed to fixate were discarded. Each session comprised $\sim 1000-1500$ stimulus presentations over the course of 40-50 min, during which time the marmoset received $\sim 500-750$ drops of reward.

fMRI testing procedures. All MRI was performed in a horizontal 7T/30 $\mathrm{cm}$ MRI spectrometer (Bruker-Biospin). For fMRI testing, the animals had no implants and were constrained during the fMRI experiments using noninvasive, custom-built helmets designed to fit the contours of the individual animals' heads (Silva et al., 2011). Each of the two individualized helmets contained an embedded eight channel surface coil array to achieve whole brain coverage with high signal-to-noise ratio (Papoti et al., 2013a, b). BOLD functional images were acquired using a gradientrecalled EPI sequence with 18 axial slices $(\mathrm{TE} / \mathrm{TR}=26 / 2000 \mathrm{~ms}$; FOV/ slice thickness $=32 \times 32 / 1 \mathrm{~mm}^{3}$; matrix $\left.=64 \times 64\right)$. A total of 512 volumes were acquired during each run. Eye position was tracked using the iView video-based tracking (SensoMotoric Instruments), and the face was monitored with an MR-compatible camera and infrared light source (MRC Systems). Visual stimuli from the same category were presented in $16 \mathrm{~s}$ blocks, with blocks of different categories randomly interleaved and separated by a fixed interval of $20 \mathrm{~s}$ in which the screen was uniformly gray. Within each block, individual stimuli from the same category were randomly selected and displayed for $500 \mathrm{~ms}$, with no gap between stimuli. Before the beginning of each block, a fixation dot appeared, to which the marmoset was required to direct its gaze within $1.5 \mathrm{~s}$, thus initiating the block sequence. If the animal failed to acquire or maintain fixation during this initial period, the block terminated and the next block began immediately. The fixation dot remained on the screen throughout each block, during which time the animal received a drop of reward every $1.5 \mathrm{~s}$ as long as it successfully maintained its gaze in the fixation window. Each run lasted $17 \mathrm{~min} 4 \mathrm{~s}$ (512 EPI volumes with TR = $2 \mathrm{~s}$ ) and consisted of up to 28 valid blocks, depending on the marmoset's performance.

Coplanar RARE $\mathrm{T}_{2}$-weighted anatomical images $\left(\mathrm{TE}_{\text {effective }} / \mathrm{TR}=64 /\right.$ $4000 \mathrm{~ms} ;$ FOV/slice thickness $=32 \times 32 / 1 \mathrm{~mm}^{3} ;$ matrix $\left.=128 \times 128\right)$ were collected each session for image registration. To visualize the highly myelinated cortical areas, $\mathrm{T}_{1}$-weighted anatomical images (MPRAGE, $\mathrm{TE} / \mathrm{TR} / \mathrm{TI} / \mathrm{TD}=3.5 / 12.5 / 1200 / 6000 \mathrm{~ms}$ ) with $0.2 \mathrm{~mm}$ isotropic resolution were collected for each animal under anesthesia after finishing all fMRI sessions. The $\mathrm{T}_{1}$-weighted images were registered to the myelination MRI atlas (Bock et al., 2011) and transformed to the atlas space for visualization purposes.

ECoG data analysis. The ECoG data were analyzed using EEGLAB (Delorme and Makeig, 2004) as well as custom codes written in MATLAB (MathWorks). We acquired 24 and 11 sessions from Marmoset $\mathrm{S}$ and Marmoset F, respectively. Local field potential signals were referenced locally by bipolar reference method. The bipolar pairs were assigned as the neighbor electrodes along the anterior-posterior direction, generating 55 rereferenced sites from 64 original electrodes. The signals were bandpass filtered using a fifth-order Butterworth filter with a window from 2 to $250 \mathrm{~Hz}$. A notch filter was used to remove $60 \mathrm{~Hz}$ line noise. There were infrequent periods of broadband noise; these periods were automatically censored by detecting high-power artifacts in the range of 70 to $200 \mathrm{~Hz}$. Epochs of $1200 \mathrm{~ms}$ for each stimulus presentation $(200 \mathrm{~ms}$ before and $900 \mathrm{~ms}$ after the stimulus) were extracted for further analysis. As there were no clear differences in response selectivity due to the size of the stimuli, the data were collapsed across stimuli size. Spectrograms
A

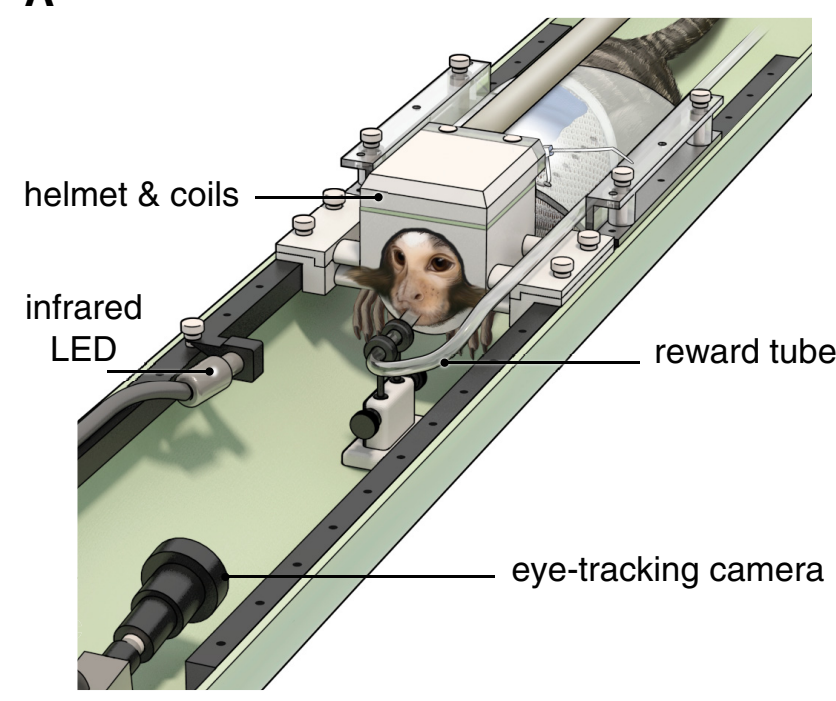

B

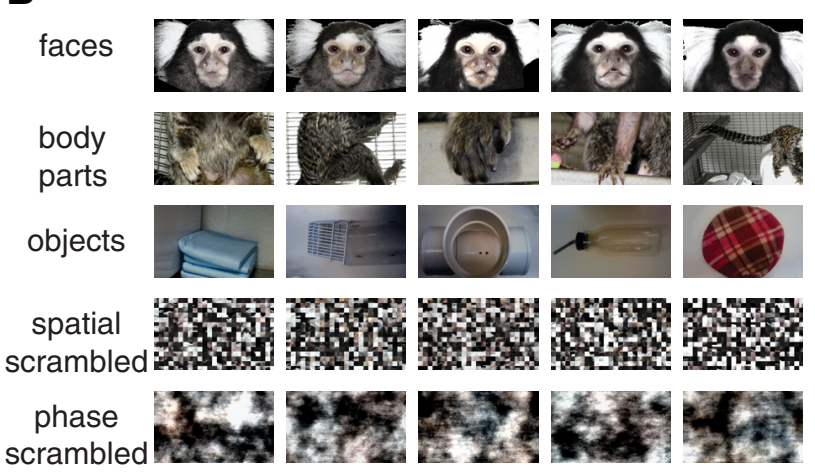

Figure 1. General experimental setup and stimuli sets. $A$, The marmosets were trained to lay in the sphinx position in an MRI-compatible cradle and acclimated to restraint by custom-made helmets in the fMRI experiment or implanted headposts in the electrophysiology experiment. The face of the animal was illuminated by an infrared light source, and task performance was monitored via eye-tracking with an MR-compatible camera. Liquid rewards for task compliance were delivered through a plastic tube positioned in the animal's mouth. $\boldsymbol{B}$, Stimuli of five different categories (faces, body parts, objects, spatial-scrambled faces, and phase-scrambled faces) were used in both the ECOG and fMRI experiments. Twenty exemplars of each category were used.

were created using Fast Fourier transforms with a running window of 200 ms throughout the $1200 \mathrm{~ms}$ epochs.

We focused on the mean time course of high-gamma local field potential power as a measure of neural activity. This measure was computed by first filtering the signals on each trial between 50 and $150 \mathrm{~Hz}$, and then calculating their mean analytic amplitude over time (Freeman, 2004). The mean signals were then smoothed for presentation purposes using a $15 \mathrm{~ms}$ Gaussian kernel with SD of $6 \mathrm{~ms}$ (see Fig. 3). To analyze and map the high-gamma responses to different stimuli at different electrodes, we quantified both the amplitude and latency of the neural response. The average amplitude was computed within a time window from 50 to 400 ms following stimulus onset (used in Fig. 8A). The response latency was defined as the moment when the unsmoothed high-gamma amplitude time course first showed a positive or negative deflection that (1) exceeded five median absolute deviations (i.e., the median of the absolute deviations from the data's median, a robust measure of the variability of a univariate sample) from the median of the $100 \mathrm{~ms}$ prestimulus baseline, and (2) continued to exceed this baseline threshold for at least $30 \mathrm{~ms}$. For Marmoset F, there were multiple sites in the dorsal row of the anterior array in which a very short latency ( $\sim 20 \mathrm{~ms})$ appeared to be superimposed on a significantly longer latency visual response. These signals were 
A

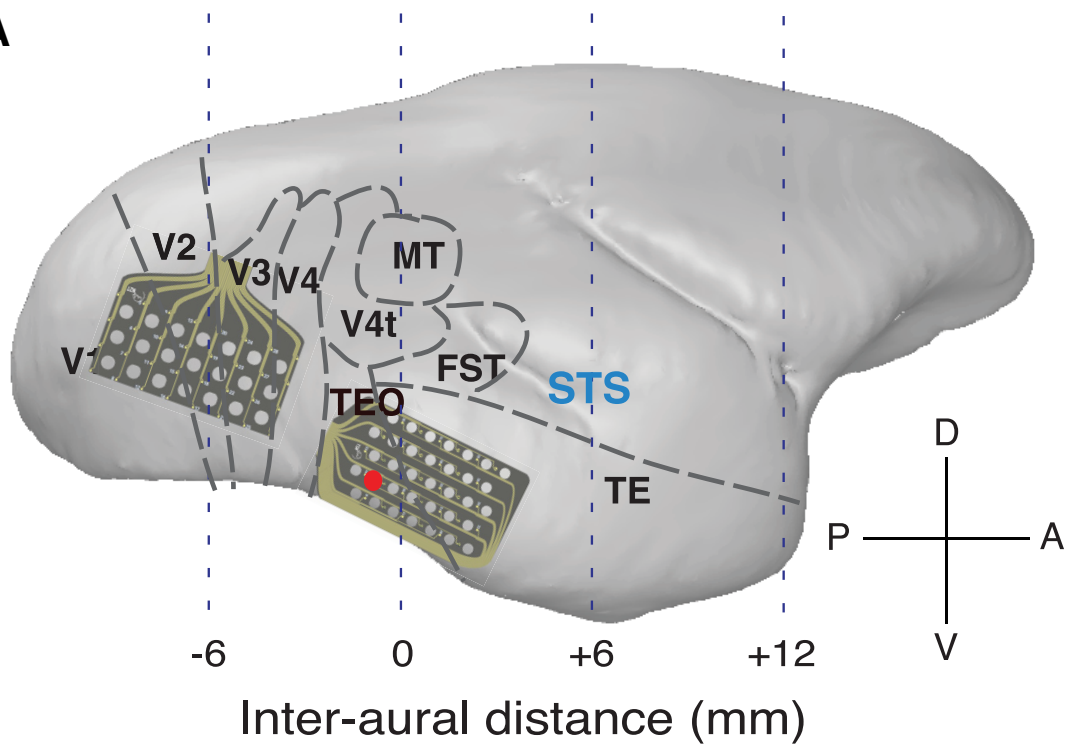

B

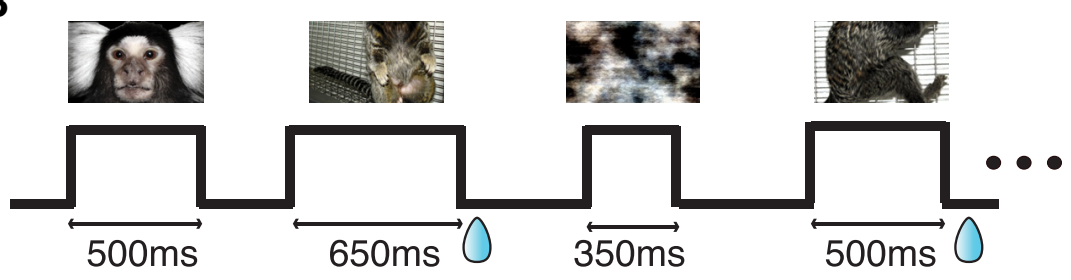

C

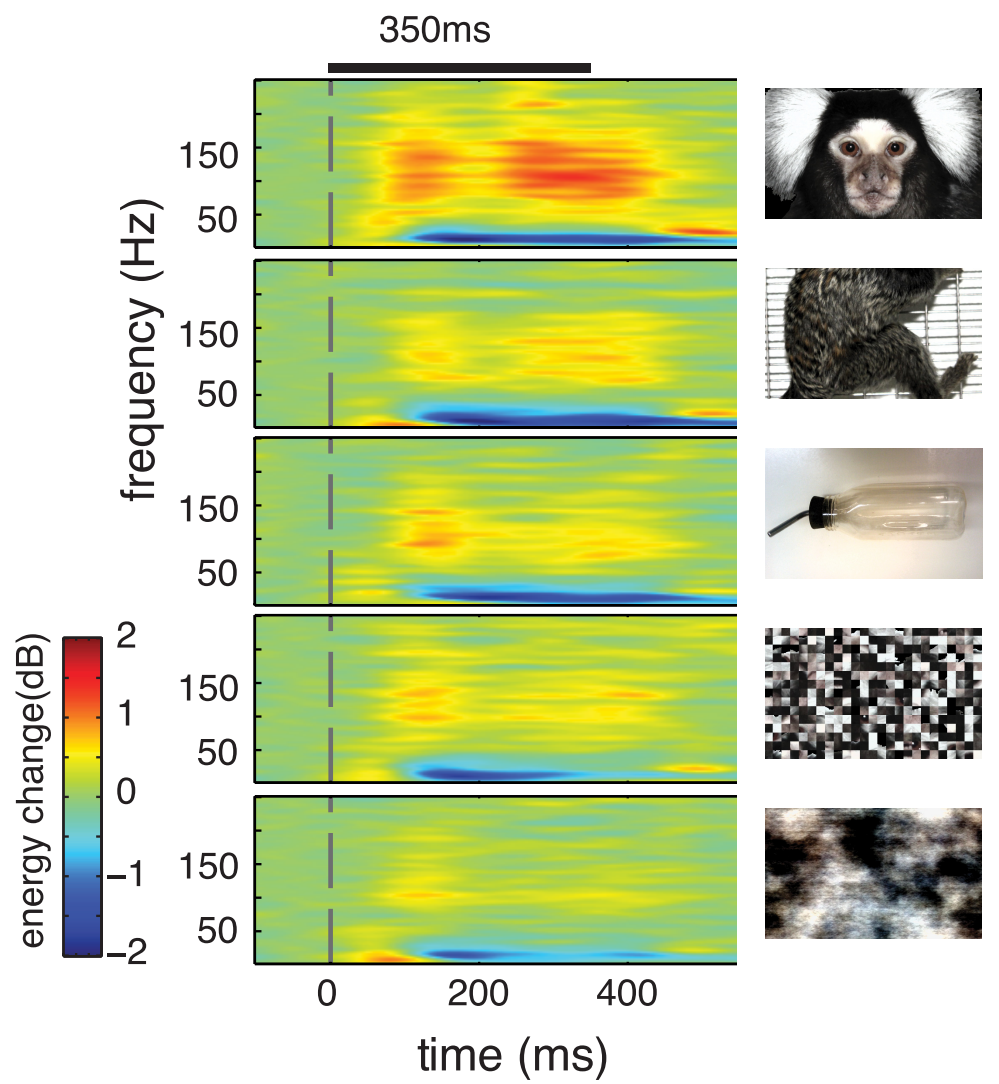

Figure 2. ECOG experiment paradigm and responses at an example site. $A$, Two marmosets were fitted with pairs of 32 channel ECOG electrode arrays implanted subdurally and positioned to cover a large swath of the extrastriate occipitotemporal cortex ranging from area V1 to area TE. The location of the ECOG arrays on Marmoset $S$ is illustrated here. Placement of the EC $0 G$ arrays was verified with anatomical MRI, and cortical area boundaries were drawn based on registration of the MRI to the marmoset brain atlas (Paxinos et al., 2011). The STS is labeled. D, Dorsal; V, ventral; A, anterior; P, posterior. B, Visual stimulation paradigm of not category selective and were presumably from the LGN, which lay directly underneath some of the contacts. To eliminate the contribution of the putative LGN response in the calculation of latency for these nine sites, we modeled the time courses with a two-peak Gaussian function and then subtracted the first Gaussian component from the raw time course. The latency was then measured in the modified time course. In 3 of the 110 sites recorded from both animals, the responses were too noisy for reliable latency measurement; thus, no latencies were reported.

fMRI data analysis. Motion-correction and cross-session alignment were performed using AFNI (Cox and Hyde, 1997). We collected 12 and 9 sessions from Marmoset $\mathrm{E}$ and Marmoset $B$, respectively. Each session consisted of 3-6 runs depending on the animal's behavioral performance of that day. Analysis was restricted to those blocks in which the animals' gaze remained within a $5^{\circ}$ radius window for $>80 \%$ ( $12.8 \mathrm{~s}$ of $16 \mathrm{~s}$ ) of the block duration. Details about the behavioral performance of each animal can be found in Tables 1 and 2 . To further minimize the contribution of movements, we excluded volumes based on combined translations and rotations, with a threshold of $0.02 \mathrm{~mm}$ for Marmoset E and 0.1 $\mathrm{mm}$ for Marmoset B. With this threshold, we censored $5.1 \%$ and $2.0 \%$ of all the collected volumes in Marmoset E and Marmoset B, respectively. Visual responses, including visual selectivity, were based on analysis of volumes collected between 4 and $18 \mathrm{~s}$ after stimulus onset. Statistical tests for stimulus selectivity during this period were based on two-sample $t$ test with correction for multiple comparisons (false discovery rate $=0.05$ ). We calculated the responses in functional regions of interest by averaging the responses of voxels in coherent patches. Patches were operationally defined for this purpose as clusters of voxels in which responses to faces exceed those to objects by at least $t>5$. The $3 \mathrm{D}$ brain surface was created by semimanually masking the cortical areas shown in the T1-weighted image using ITKsnap (Yushkevich et al., 2006) and Caret (Van Essen, 2012). The functional data were projected onto this surface using the Caret algorithm, which takes a weighted average of the functional data from voxels nearby each surface vertex (Van Essen, 2012). The final surfaces and the functional maps were rendered using custom code written in MATLAB.

the $\mathrm{ECOG}$ experiment. Stimuli were shown in random order with an equal possibility of 350,500 , or 650 ms duration. Liquid rewards were given every two stimuli presentations during the interstimulus intervals if the animals maintained gaze inside a $5^{\circ}$ window. $C$, Time-frequency analysis of five stimuli categories at an example site in area TEO ( $\boldsymbol{A}$, red dot). Sustained high-gamma $(50-150 \mathrm{~Hz})$ power increases and beta band $(15-30 \mathrm{~Hz}$ ) power decreases were observed for all stimuli categories. The site also showed a response preference for faces, followed by body and objects, with lower responses to control stimuli. 

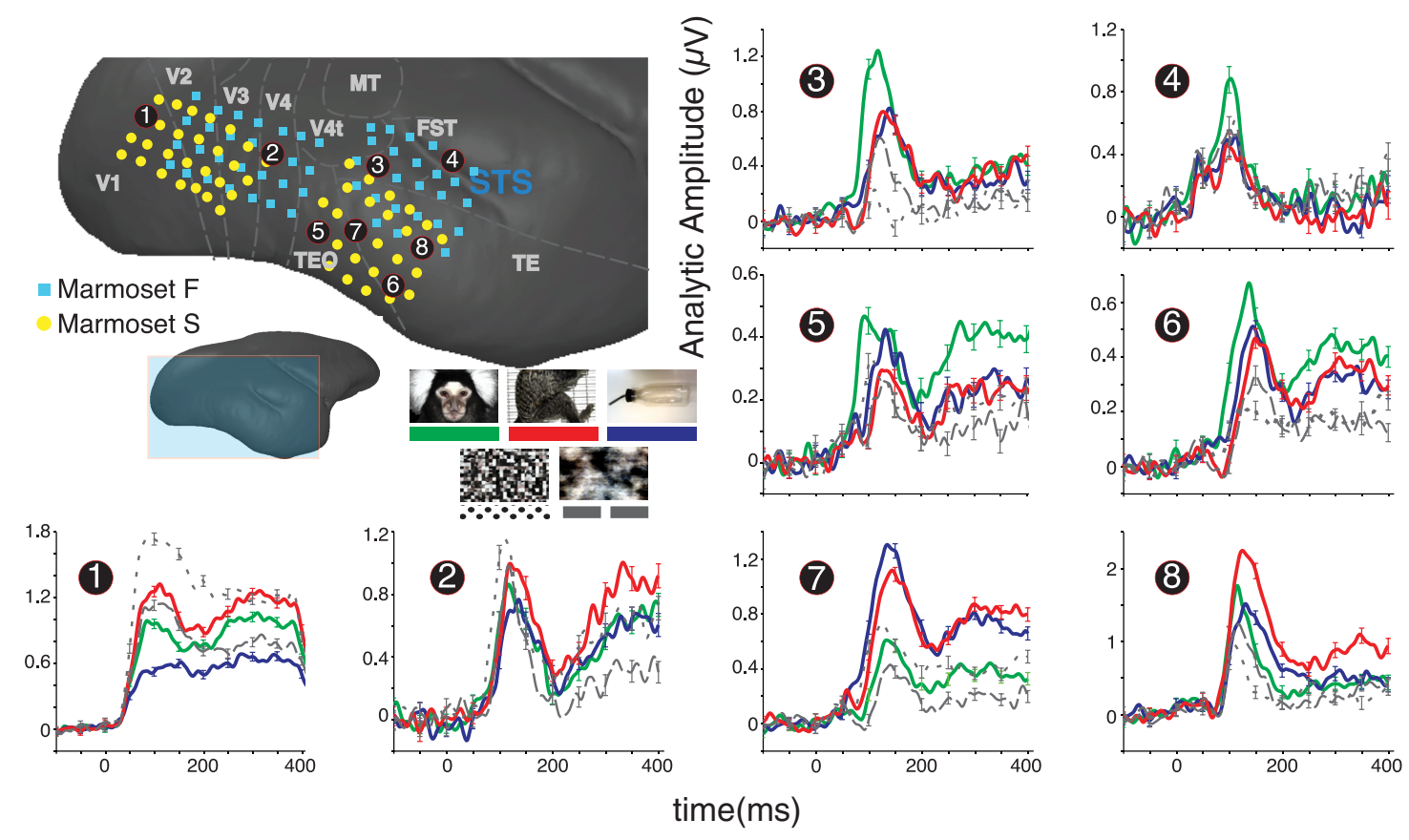

Figure 3. Diverse high-gamma power selectivity of stimuli categories across occipitotemporal cortex. All 110 bipolar-referenced sites (yellow sites from Marmoset S; cyan cites from Marmoset F) are illustrated on the occipitotemporal cortex. Inset, Area shown in magnification. The high-gamma ( $50-150 \mathrm{~Hz})$ power changes are shown for 8 representative sites, with time courses colored by stimulus type (green represents faces; red represents body parts; blue represents objects; dots indicate spatially scrambled images; hatches indicate phase-scrambled images). Error bars indicate SEM and are drawn every $50 \mathrm{~ms}$. Site 1: located posteriorly, in V1, responded stronger to spatial-scrambled images. Site 2: located more anteriorly than Site 1, in V4, started showing selectivity to structured stimuli, especially in the sustained response period. Sites 3-6: four distinct face-selective sites located in different parts of the temporal cortex. Sites 3 and 4, near STS, showed transient face-selective responses, whereas Sites 5 and 6, located more ventrally in TE 0 and TE, respectively, exhibited sustained selective responses to faces. Sites 7 and 8 , also in TE, had selective responses to body parts and objects.

Mapping foveal representation with $\mathrm{FMRI}$. In one of the fMRI animals (Marmoset B), we mapped the cortical foveal representation. For this experiment, we employed ultrasmall superparamagnetic iron oxide nanoparticles (USPIOs) $(20 \mathrm{mg} / \mathrm{kg}$ IV, fabricated by the NIH Imaging Probe Development Center) to serve as an intravascular contrast agent. For mapping the foveal representation, the animal was presented with a block-design stimulus paradigm consisting of four 16 s blocks of different flashing checkerboard patterns displayed at the screen's periphery $\left(3^{\circ}-10^{\circ}\right.$ visual angle) (see Fig. $9 A$ ). To encourage the animal to restrict its gaze to the center of the screen, the fixation dot was replaced by a small ( $3^{\circ}$ visual angle) movie of marmoset scenes. To estimate the central ("foveal") cortical representation, we identified voxels with a percentage signal change $>1.5 \%$ and a coefficient of variation $<3.5$ in all four stimulation blocks. In addition, only voxels with a maximum response difference of $30 \%$ across all four blocks were considered. The color coding of the foveal representation (see Fig. $9 \mathrm{~B}$ ) shows the consistency (range $70 \%-100 \%)$ of the responses across all four blocks.

Color coding the category selectivity of the fMRI and ECoG data. Colors to indicate selectivity among faces (green), body parts (red), and objects (blue) were assigned for each voxel in the fMRI data or each electrode site in the ECoG data. We adopted the HSL (hue, saturation, and lightness) cylindrical color coordinates. The hue, the angle on the cylindrical color coordinates, was determined by stimulus preference. The saturation and lightness were used to represent the strength of the selectivity weighted by the relative responses to scrambled images.

Functional responses to faces, body parts, objects, and the two scrambled sets were first normalized to the largest response for each voxel or electrode site. The categorical selectivity strengths to faces $(f)$, bodies $(b)$, and objects $(o)$ were then calculated as the difference in the response to the targeted stimuli and to the scrambled set with higher response. If the response to the scrambled set was higher than that to the target stimuli, the categorical selectivity strength would be set to 0 . The point on color wheel $(p)$ was then calculated using a vector sum as follows:

$$
p=f \cdot \vec{G}+b \cdot \vec{R}+o \cdot \vec{B},
$$

where $\vec{G}, \vec{R}$, and $\vec{B}$ are unit vectors pointing to pure green, red, and blue, respectively, at the rim of the color wheel. In the resulting functional maps, regions with brightly saturated colors indicate strong category selectivity and relatively low responses to the scrambled images, whereas dimly unsaturated areas indicate low category selectivity or relatively high responses to the scrambled images.

\section{Results}

We measured cortical responses to faces and other object categories in four marmosets trained to direct their gaze toward images presented on a color display. The animals' heads were held firmly using implanted headposts in the electrophysiology experiments and noninvasive customized helmets in the fMRI experiments. The animals' eye position was tracked throughout all experiments using a video-based eye-tracking system. During testing, the animals were rewarded for maintaining their gaze upon the stimuli (Fig. 1A). The same stimulus set was used in the electrophysiology and fMRI experiments. The stimuli consisted of three main categories and two controls. The three main categories included 20 exemplars of conspecific faces, conspecific body parts, and manmade objects familiar to the animals. Control stimulus categories consisted of spatial- and phase-scrambled images of the faces (Fig. 1B). The following sections describe the responses in the marmoset brain to the different stimulus categories, beginning with the neuronal activity recorded using ECoG arrays.

\section{Face-selective neuronal responses in the ventral pathway}

We measured field potentials across a large swath of the occipitotemporal cortex of two marmosets (Marmoset F and Marmoset S) using implanted pairs of 32 channel ECoG arrays (Fig. 2A). The lissencephalic nature of the marmoset cortex allowed for a spatially continuous sampling of the ventral visual pathway from 
V1 to TE. Briefly presented images of faces, bodies, objects, and control patterns were interspersed with blank periods and randomly interleaved across trials (Fig. 2B).

We focused on category-specific changes in band-limited ECoG power changes, using bipolar referencing of each electrode to optimize measurement of local neural activity (see Materials and Methods). Most ECoG sites showed robust visual responses in the form of sustained power increases in the high-gamma band $(50-150 \mathrm{~Hz})$ accompanied by decreases in the beta band (15-30 $\mathrm{Hz}$ ). An example broadband response is shown in Figure $2 C$, in which a site in area TEO responded most strongly to faces. As the high gamma frequency range has previously been linked to neural spiking in the vicinity of the electrode (Crone et al., 2006; Ray and Maunsell, 2011), we focus the remainder of our analysis on this signal as the basis for determining local visual selectivity.

The locations of all 110 sites from the two implanted marmosets are illustrated in Figure 3. Time courses of the high-gamma band power are shown across all stimulus categories for eight representative sites. Site 1 in V1 responded most strongly to finely scrambled stimuli. This characteristic was typical of posterior recording locations. Somewhat more anterior sites, such as Site 2 in V4, showed less of a preference for the scrambled images, especially in the second plateau phase of the response (after 200 $\mathrm{ms})$. Sites 3-6 are representative face-selective sites positioned in distinct regions of temporal cortex, in this case from four different face patches. The more dorsal face-selective sites near the superior temporal sulcus (Sites 3 and 4) showed transient responses, whereas the more lateral and ventral face-selective sites (Site 5 in TEO and 6 in TE) were more sustained in their faceselective responses. The enhanced response for faces cannot be ascribed to a simple attention effect because other simultaneously recorded sites at nearby locations in TE responded with different patterns of category selectivity (e.g., Sites 7 and 8).

The spatial layout of the arrays allowed for characterization of visual response properties along a nearly continuous span of the ventral visual stream. In one analysis, we found there to be a gradual transition in the preference for stimulus structure, with responses at more posterior sites showing preference for finely scrambled stimuli and more anterior sites showing responses for structured stimuli $(r=0.61, p<0.001$; Fig. $4 A)$. In another analysis, we found that the response latencies exhibited a coarse posterior-to-anterior gradient $(r=0.68, p<0.001$; Fig. $4 B)$ that presumably reflected the stepwise propagation of visual signals along the occipitotemporal pathway. A few sites in anterior positions violated this trend and had very short latencies $(\sim 50 \mathrm{~ms}$; Fig. 4B). These short-latency sites were within the superior temporal sulcus (STS) and were primarily selective for faces. These sites, together with other face-selective anterior sites that had a much longer latency, are suggestive of two parallel pathways for ventral stream face processing, as has been suggested in humans and macaques (Calder and Young, 2005; Pinsk et al., 2009; Yovel and Freiwald, 2013). The coloring of the dots in Figure 4 indicates higher category selectivity at more anterior sites. The basis for coloration is described in more detail in the section "Spatial organization of visual category selectivity" below.

\section{Face-selective areas revealed by fMRI BOLD contrast}

To gain a broader picture of face selectivity across the brain, we performed fMRI experiments in the other two marmosets (Marmoset $\mathrm{E}$ and Marmoset $\mathrm{B})$. We trained the animals to perform the task in a 7T horizontal scanner (Bruker-Biospin) while their heads were comfortably restrained using individualized, custombuilt helmets that contained embedded eight channel radiofre-
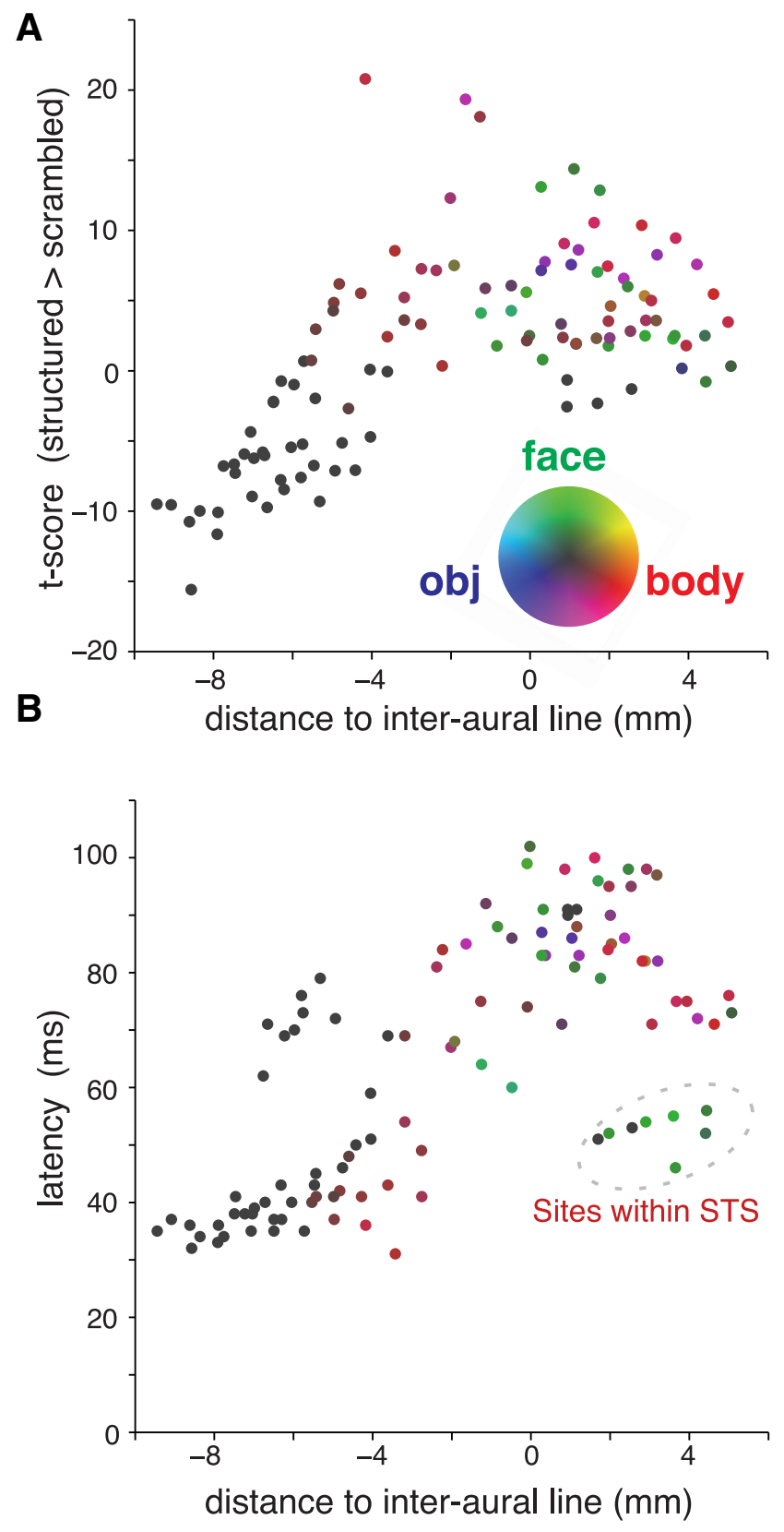

Figure 4. Structure selectivity and response latency along the occipitotemporal axis. $\boldsymbol{A}$, There was a positive correlation between the sites' coordinates in the anterior-posterior direction and the response selectivity for structured versus scrambled stimuli (Pearson correlation $=0.61, p<0.001)$. $\boldsymbol{B}$, There was a positive correlation between the sites' coordinates in the anterior-posterior direction and the latencies of the corresponding high-gamma responses (Pearson correlation $=0.68, p<0.001$ ). Electrode sites are color-coded for their relative response strength to faces, body parts, and objects. Sites within STS, including the faceselective sites indicated in green, possess shorter latencies compared with other sites with comparable anterior-posterior coordinates.

quency receiving coils (Fig. 5A) (Silva et al., 2011; Papoti et al., 2013a, b). We presented the same sets of category-specific stimuli as before. However, now the stimuli were shown in a block design paradigm, in which each 16-s-long block consisted of a sequence of images selected randomly from a single category and presented every $0.5 \mathrm{~s}$ (see Materials and Methods; Fig. 5B). During the behavioral task, we acquired BOLD responses at a spatial resolution of $0.5 \times 0.5 \times 1.0 \mathrm{~mm}$. Visual responses were observed throughout the occipitotemporal visual cortex for all categories of visual stimuli, typically reaching $0.5 \%-3 \%$ 
BOLD signal changes in individual voxels The time courses of the signals revealed a clear and sustained, blockdriven hemodynamic response that reached a maximum at $\sim 4 \mathrm{~s}$ after block onset.

We asked whether these fMRI responses were selective for individual stimulus categories. To address this question, we contrasted the fMRI response magnitude between faces and objects, a common contrast used in fMRI studies in humans (Kanwisher et al., 1997) and macaques (Tsao et al., 2003). The resulting fMRI maps identified at least five circumscribed cortical regions that responded more strongly to faces than to objects. These face-selective patches, together with regions responding less to faces than to objects, are shown on a surface activity map of the right hemisphere of Marmoset $\mathrm{E}$ ( $t$ test, $p<0.05$, corrected for multiple comparisons; Fig. 6A). This activity was also visible directly on parasagittal slices (Fig. 6B).

We focused on the temporal lobe regions in which faces elicited stronger responses ("face patches," Fig. 6C). We labeled these areas based on their positions within the occipitotemporal cortex, approximating a naming convention applied previously in the macaque (Moeller et al., 2008). For each patch, the position within known extrastriate areas was determined based on registration with a recently published atlas of the marmoset brain (Paxinos et al., 2011). From anterior to posterior, these consisted of an $\mathrm{AD}$ (anterior dorsal) and a MD (middle dorsal) patches along STS, a PD (posterior dorsal) patch in area V4t/FST, a PV (posterior ventral) patch at the V4/TEO border, and an $\mathrm{O}$ (occipital) patch at the V2/V3 border. For reference in Figure $6 C$, we also mark the position of face-selective area MV (middle ventral) more ventrally in TE, which was observed in the ECoG recordings but not visible in fMRI due to basal susceptibility-induced artifacts.

In addition to the atlas registration, we further confirmed the anatomical location of the face patches by comparing the functional maps to a high-resolution cortical myelogram obtained previously from five other marmosets. The level of cortical myelination was determined with $\mathrm{T}_{1}$-weighted images (Bock et al., 2009, 2011). Primary sensory areas and visual areas MT and DM show higher myelination than other cortical areas (Fig. 6C, inset). Overlapping the face patches with the boundary drawn from cortical myelination (Fig. 6C, white dashed lines), we found that face area PD is outside and ventral to area MT, in a location consistent with the location of areas V4t and FST in the atlas (Paxinos et al., 2011) and that face area $\mathrm{O}$ is primarily within areas V2/V3.

A

B
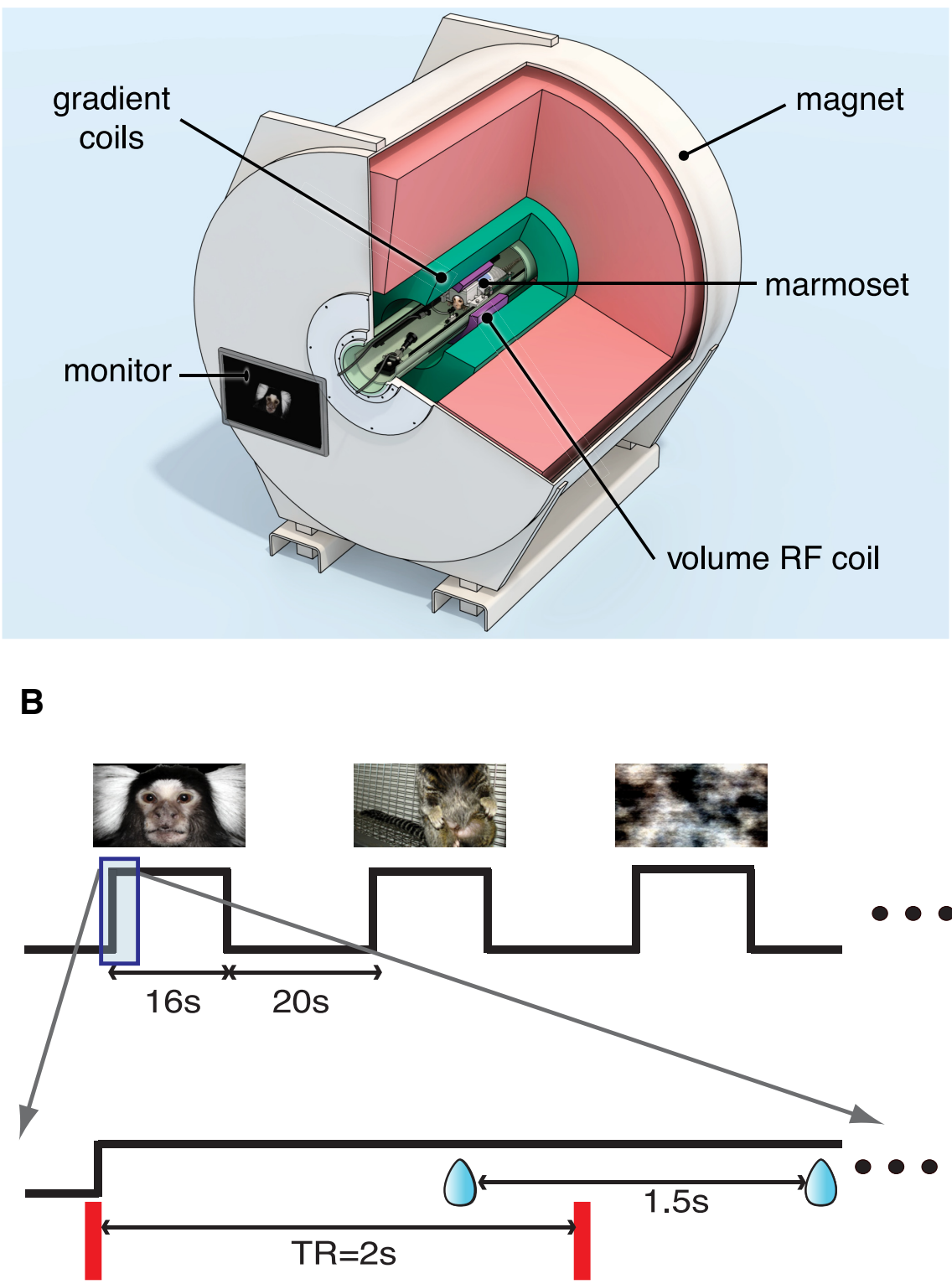

Figure 5. fMRl experiment setup and paradigm. $\boldsymbol{A}$, Two other marmosets lying in the sphinx position with custom-made helmets were scanned in a horizontal $7 T / 30 \mathrm{~cm}$ MRI spectrometer. Visual stimuli were presented on an LCD monitor placed outside the magnet. $\boldsymbol{B}$, During the fMRI experiment, visual stimuli were presented using a block design paradigm in which individual stimuli of the same category were displayed in randomized order every $500 \mathrm{~ms}$ during a $16 \mathrm{~s}$ block. A fixed interblock interval of $20 \mathrm{~s}$ was used, and each run consisted of up to 28 blocks. Whole-brain multislice MRI images were acquired every $2 \mathrm{~s}$. The marmosets were rewarded every $1.5 \mathrm{~s}$ for maintaining their gaze inside a $5^{\circ}$ radius window.

Figure 7 shows BOLD fMRI signal time courses for each of the face patches. Within each patch, faces elicited higher fMRI responses, with a gradation across the other categories that differed between the patches. The fMRI time courses suggest a progression of face selectivity within the occipitotemporal pathway. Specifically, $\mathrm{AD}$ and $\mathrm{MD}$ responded almost exclusively to faces, $\mathrm{PV}$ and $\mathrm{PD}$ showed intermediate responses to bodies and objects as well, and $\mathrm{O}$ responded strongly to all three categories, with a small but highly significant preference for faces.

\section{Spatial organization of visual category selectivity}

To summarize the category selectivity observed in both the ECoG and fMRI data, we created spatial maps of relative re- 
A
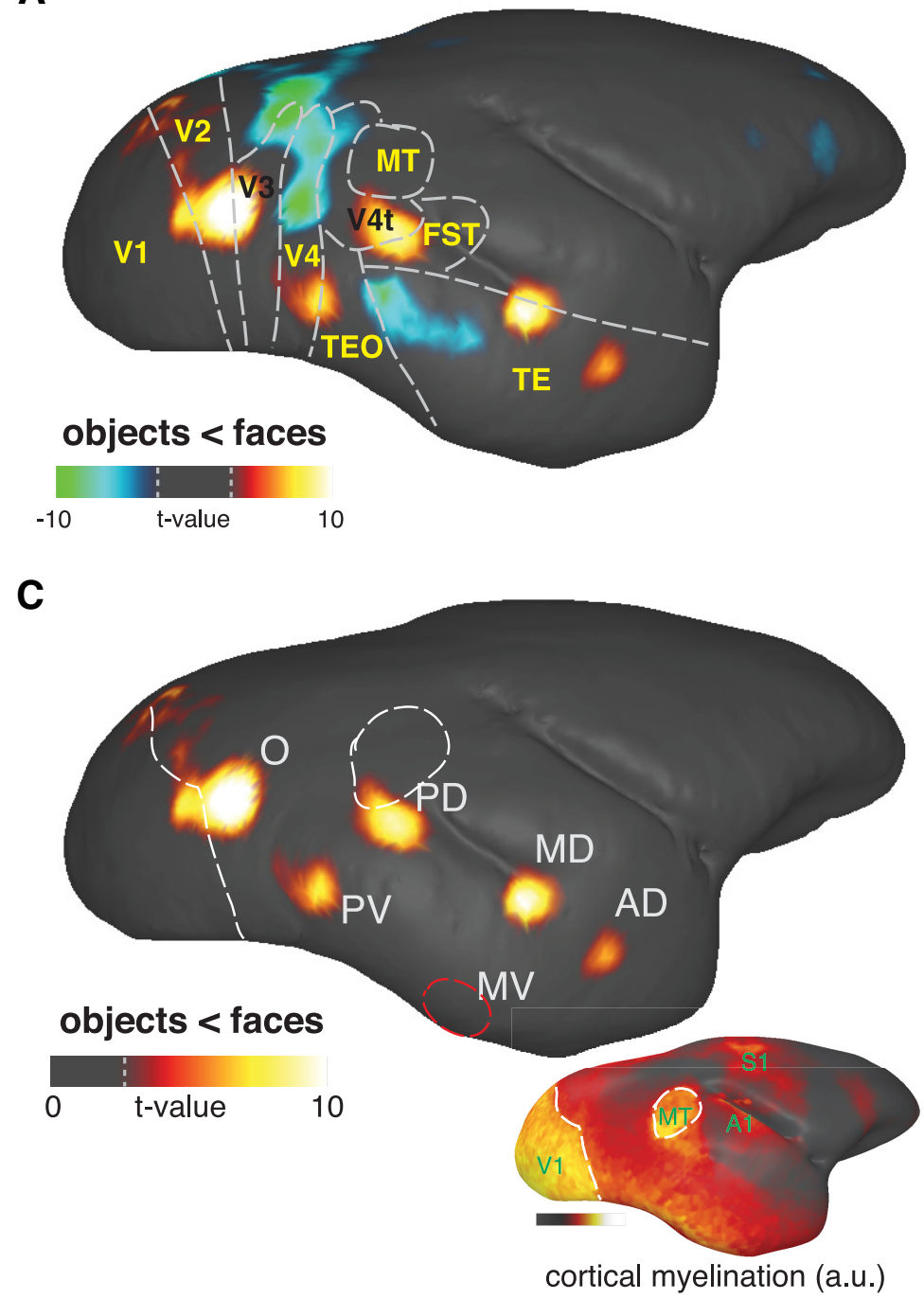

B
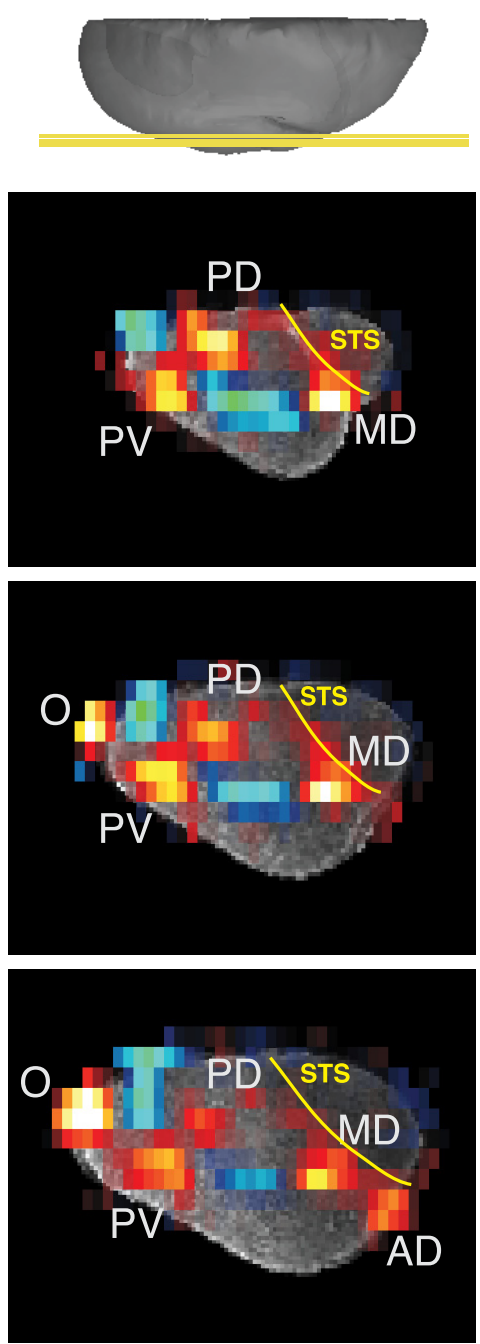

objects < faces

$-11$

t-value

11

Figure 6. Five face-selective areas across extrastriate visual cortex identified with fMRI. $A$, Functional map contrasting faces versus objects reveals five discrete functional areas, overlaid here on the right hemisphere of Marmoset $E$. Color bar represents the $t$ value scale. Dashed line indicates the $t$ value corresponding to a $p$ value $=0.05$ after correcting for multiple comparisons. No specific threshold was applied to the map; instead, we used a gradual transparency scale to indicate the significance of the data. $\boldsymbol{B}$, Three parasagittal slices (at 11.6, 11.1 , and $10.6 \mathrm{~cm}$ from midline) are shown with the same functional map contrast as in $A$. The face patches are easily identified in this raw format. All five face-selective areas are observed in the slice $10.6 \mathrm{~cm}$ from the midline (bottom). C, Only the positive contrast of the faces versus objects map is shown here to highlight the five face-selective areas. Top left to bottom right, Face patches 0 (V2/V3), PV (V4/TE0), PD (V4t/FST), MD (posterior TE), and AD (anterior TE). A sixth face patch, indicated by a red circle and labeled area MV, was detected with ECoG but not with fMRI due to signal dropout. Right inset, Cortical myelination strength obtained with T1-weighted MRI from five other animals. Areas V1, A1, S1, and MT show stronger myelination compared with other areas. The boundary of V1 and MT is delineated in the main figure. Face patch PD is outside and ventral to area MT, in a location consistent with the location of areas V4t and FST in the atlas. Face patch 0 is anterior to area V1 and is located within areas V2/V3.

sponses to faces, body parts, and objects along the occipitotemporal pathway. We assigned a color to each single electrode site or voxel (see Materials and Methods) based on the category selectivity. As shown in the color wheel (Fig. 8), pure green, red, and blue indicated that a site responded exclusively to faces, body parts, or objects, respectively. Other "intermediate" colors, such as orange, cyan, and purple, indicated prominent responses to more than one category. Low category selectivity, or stronger responses to scrambled than to structured stimuli, are reflected in less saturated, grayish colors. The selectivity map of the electrophysiology data (Fig. $8 A$ ) revealed four face-selective electrode clusters in face patches $\mathrm{PV}, \mathrm{MV}, \mathrm{PD}$, and $\mathrm{MD}$, interleaved with zones of sites in V4 and TE responsive to body parts and, to some extent, objects. This category selectivity stood in sharp contrast to the stronger responses to scrambled stimuli found in the posterior sites, which appear gray. The same color scheme was used to indicate the category selectivity of the dots in Figure 4.

The functional ECoG map can be compared directly with the corresponding map of the fMRI selectivity computed using the same measure, shown in Figure $8 B$. In the fMRI map, it is evident that the more anterior patches also have more saturated colors, particularly the green face-selective regions. Similar to the ECoG results, these face patches were interleaved with regions in V4 and 


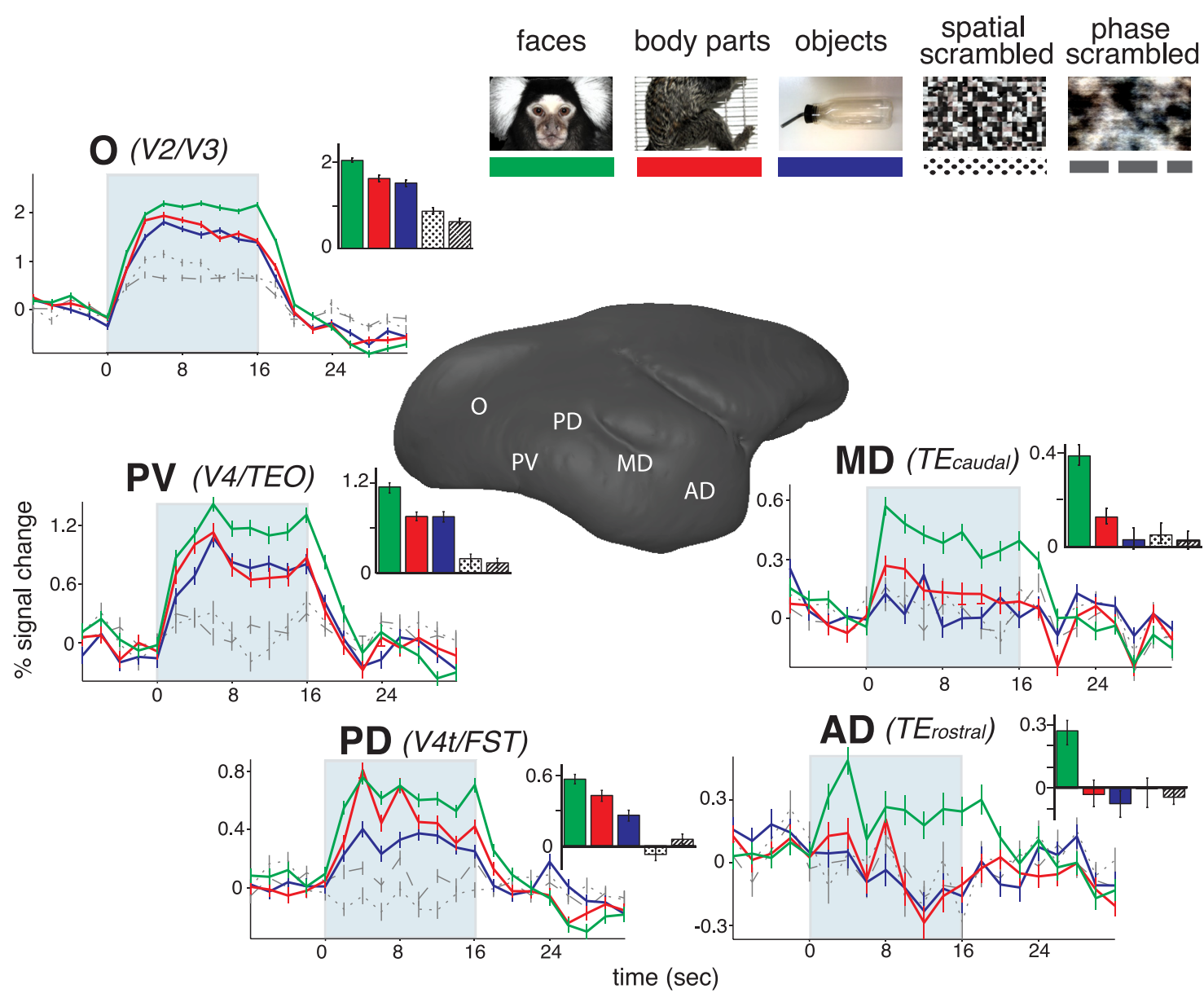

Figure 7. Time courses and selectivity of face-selective areas. The time courses of the BOLD signal changes to each stimulus category (green represents faces; red represents body parts; blue represents objects; dots indicate spatially scrambled images; hatches indicate phase-scrambled images) compared with the fixation dot alone condition are plotted for the five fMRl-identified face-selective functional regions. Error bars in the time courses indicate SEM. Median percentage signal changes relative to the fixation dot alone condition are shown in the corresponding insets. Error bars indicate $95 \%$ confidence intervals calculated by bootstrapping.

TE that responded more strongly to body parts and objects. We did not find any locations in our fMRI experiments that responded selectively only to body parts or objects. However, some areas on the margins of the face patches responded to both body parts and faces (yellow-colored voxels). This finding is broadly consistent with previous findings in macaques and humans of body-selective areas located directly adjacent to face patches (Tsao et al., 2003; Peelen and Downing, 2007; Weiner and GrillSpector, 2013).

Finally, we investigated the relationship between the face patches and the retinotopic foveal representation in the extrastriate cortex of Marmoset B (Fig. 9). Using a technique in which the marmoset maintained its gaze on a small $3^{\circ}$ diameter movie presented at the center of the screen, we mapped the stimulated voxels throughout the visual pathway (see Materials and Methods). The resulting map revealed a large cortical area extending from V1 to V4 that contained the expected pattern of foveal representation, with a few additional smaller islands of positive activity, including area MT (indicated by the white arrow). Superimposition of the outlines of the face patches obtained from this same animal (Fig. 10B) onto this map (dashed outlines) revealed no obvious relationship. The most posterior face patch $\mathrm{O}$ shared some overlap with the ventral portion of the foveal representation, but there was minimal overlap with the other face patches. This finding is similar to recent observations in the macaque (Janssens et al., 2014, their Fig. 6C) and is generally inconsistent with the idea that face patches are specializations of foveally biased extrastriate regions (Hasson et al., 2002), although clearly more work is needed on this important topic.

\section{Consistency across animals, stimulus scale, and sessions}

We conducted additional analyses and experiments to evaluate the robustness of the face-selective responses. First, we compared the fMRI maps of category-selective responses across hemispheres and across animals (Fig. 10). The face patches were more pronounced in the right hemisphere in both animals. In one of the animals, we also observed a face-selective region in the prefrontal cortex (Fig. 10B). Importantly, all five fMRI-identified patches were observed in both hemispheres of each animal. Second, we analyzed separately the odd and even sessions from different days of both the fMRI and the ECoG analysis and showed that in each case the spatial pattern of selectivity was reproducible (fMRI in Fig. 11A; ECoG in Fig. 11B). Finally, control experiments from two fMRI sessions demonstrated that the face patches were robust over more than a twofold range of stimulus sizes $\left(3^{\circ}-7^{\circ}\right)$. All five face patches found within the main fMRI experiment were still visible by contrasting various sizes of faces to body parts (Fig. 11C). 

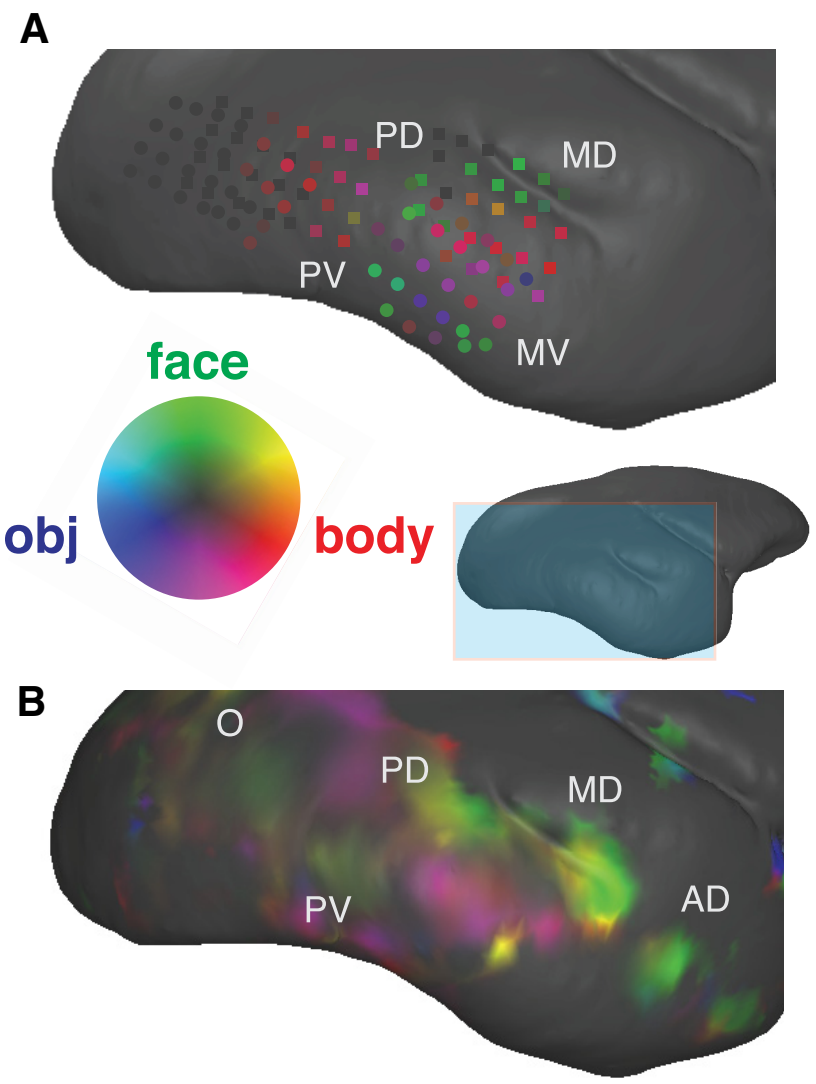

Figure 8. Color-coded functional selectivity maps for faces, body parts, and objects obtained from $E C O G$ and $f M R l$ experiments. $A$, Electrode sites are color-coded for their relative responsestrength to faces, body parts, and objects. Green represents four distinctive face-selective areas (PV, PD, MD, and MV), interleaved with zones of sites in V4 and TE responsive to body parts and objects. The selectivity strength, like the preference for intact stimuli, exhibits a pronounced posterior-to-anterior gradient. $\boldsymbol{B}$, Same color coding method applied on the fMRI data. The more anterior face patches had stronger selectivity than the more posterior ones, as shown with higher saturation.

A
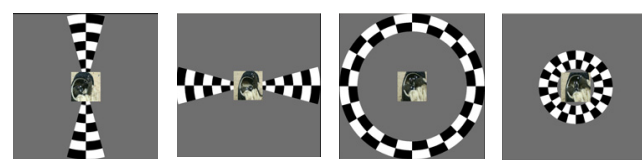

B

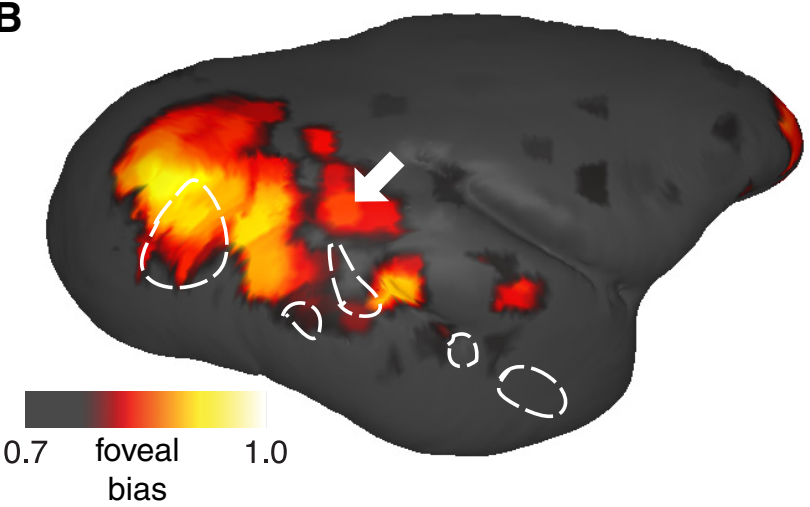

Figure 9. Layout of the face patches relative to the cortical foveal representation. $\boldsymbol{A}$, Four $16 \mathrm{~s}$ blocks of checkerboard wedges or rings at the periphery $\left(3^{\circ}-10^{\circ}\right.$ visual angle) with the fixation dot replaced by a small ( $3^{\circ}$ diameter) movie of marmoset scenes. $\boldsymbol{B}$, The foveal representation was mapped by identifying the voxels with significant and consistent responses to all four stimulation blocks. The map is shown on the right brain surface of Marmoset B. Color coding represents the similarity of the response across the four different stimulus conditions (range 70\%-100\%). White arrow indicates area MT. The outlines of this animal's face patches are marked by dashed boundaries.
A

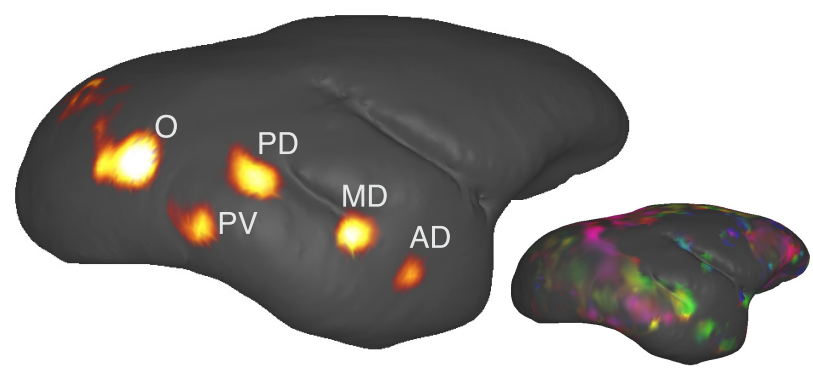

objects $<$ faces

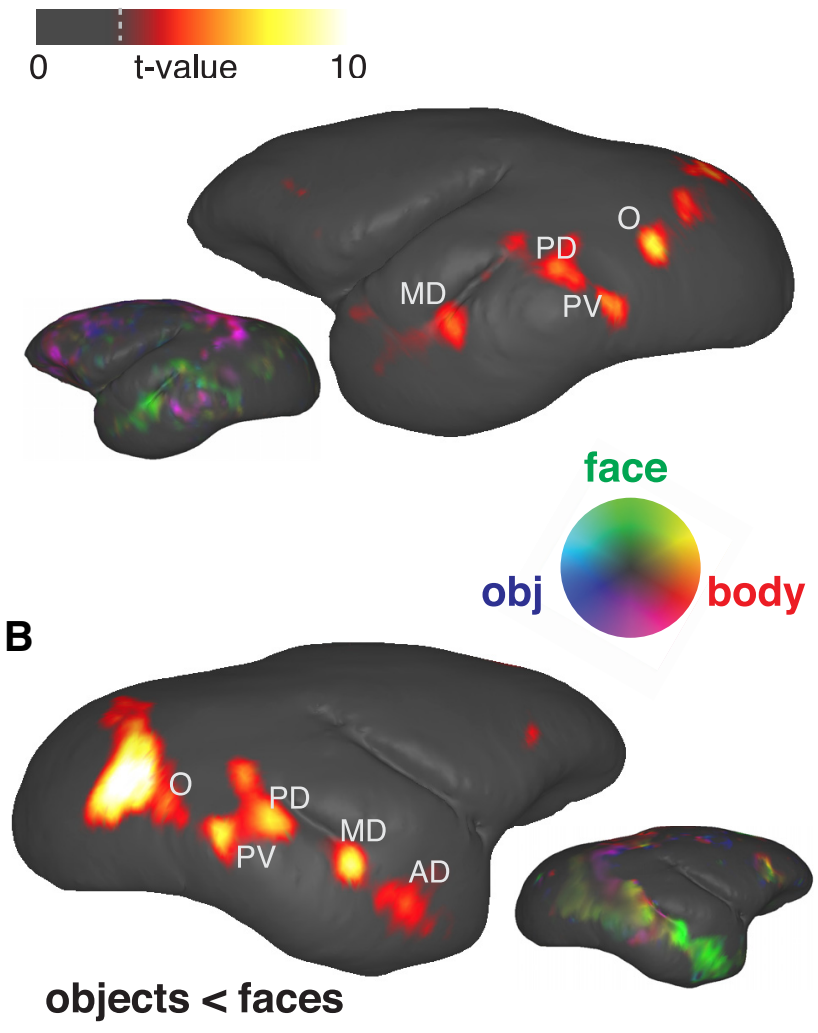

$0 \quad$ t-value 15

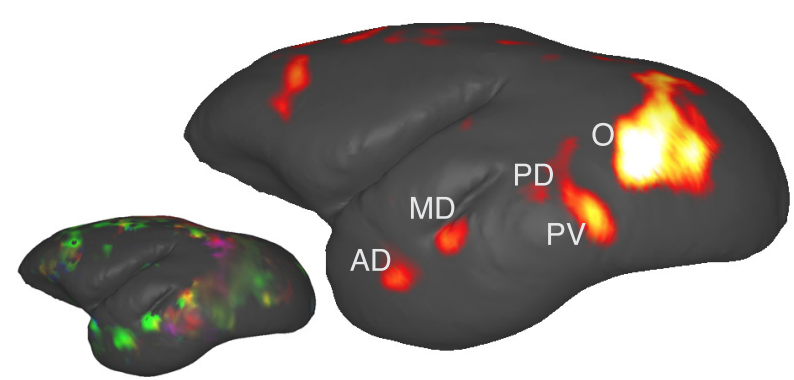

Figure 10. Consistent face patches and general organization in both hemispheres of two subjects. The contrast map between faces and objects in four hemispheres: $A$, The right hemisphere (top) and the left hemisphere (bottom) of Marmoset E. B. The right hemisphere (top) and the left hemisphere (bottom) of Marmoset $B$. Color bar represents the $t$ value scale. Dashed lines indicate the $t$ value corresponding to a $p$ value $=0.05$ after correcting for multiple comparisons. The color-coded selectivity maps are shown on the inset of each corresponding hemisphere. The layout of the five face patches found with fMRI is similar for both hemispheres across subjects. 
A

A odd sessions

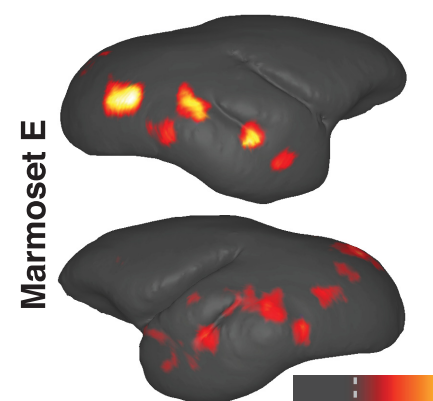

0 t-value

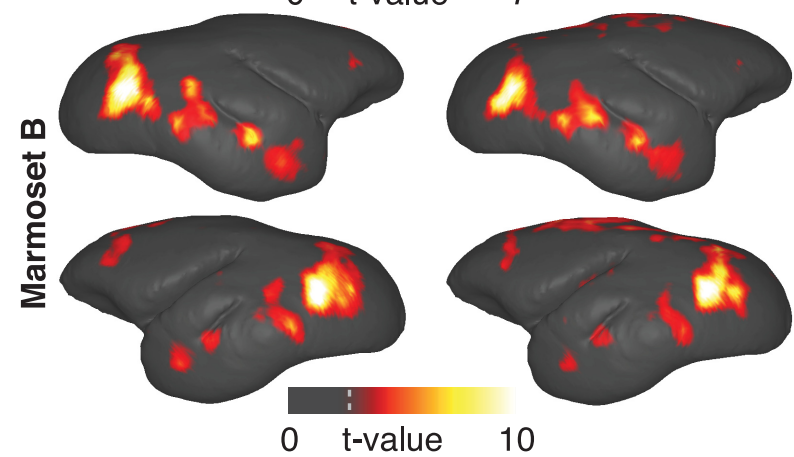

B

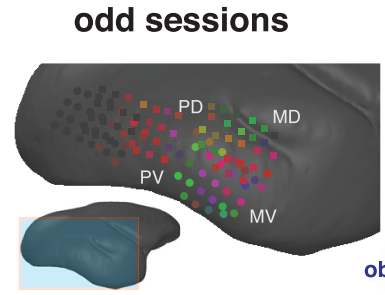

C

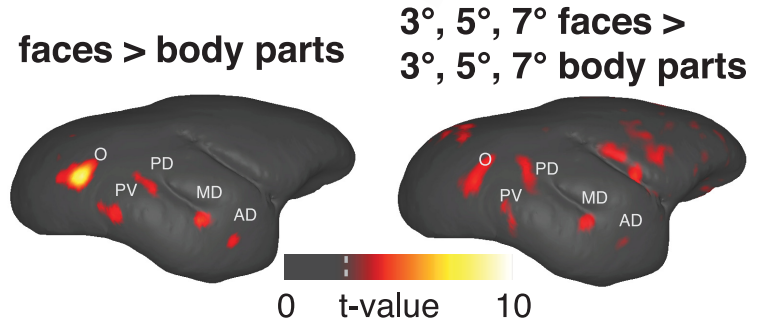

Figure 11. Consistency of the fMRI results. $\boldsymbol{A}$, The layout of the face patches identified with fMRI on all four hemispheres of the two animals were highly similar when contrasting faces and objects using only odd (left column) or even (right column) sessions from different days of data acquisition. $\boldsymbol{B}$, The same odd-even analysis showed that the face patches and category selectivity identified with $\mathrm{ECOG}$ on the two animals were also comparable. C, Functional contrast maps of face versus body using $5^{\circ}$ stimuli in the main experiment (left) and using varying stimulus size $\left(3^{\circ}-7^{\circ}\right)$ in control experiments (right). The locations of the face-selective areas are similar in both conditions. Color bar represents the $t$ value scale. Dashed lines indicate the $t$ value corresponding to a $p$ value $=0.05$ after correcting for multiple comparisons.

\section{Discussion}

Comparing face-selective regions in marmosets, macaques, and humans

This study reveals multiple visual cortical regions specialized for processing faces in the common marmoset. To the best of our knowledge, the present study is the first to systematically map high-level visual selectivity in awake, behaving animals other than macaques and humans. Although further comparative work is necessary to determine the precise areal homology between primate species, the overall arrangement of face patches in the marmoset brain, and their approximate distribution in the occipitotemporal cortex, appears very similar to macaque and human (Tsao et al., 2008; Lafer-Sousa and Conway, 2013).

The two most anterior face patches along the marmoset STS (MD and $\mathrm{AD}$ ) are similar in position to the macaque middle $(\mathrm{MF} / \mathrm{ML})$ and anterior $(\mathrm{AF} / \mathrm{AL})$ face patches, respectively. Their positions also bear resemblance to two face-selective patches in anterior and posterior STS of the human (Carlin et al., 2011; Pitcher et al., 2011), although the correspondence between the macaque and human is presently a matter of speculation (Yovel and Freiwald, 2013). The marmoset PV patch is also coarsely similar in position to macaque $\mathrm{PL}$, although extended more posteriorly than in the macaque, into V4. The PD patch, which is located in V4t/FST, is similar in position to a recently described face-selective patch pPL in macaque V4t (Janssens et al., 2014). Based on its topological position, the most ventral face patch MV, which we discovered using ECoG recordings, is a putative homolog with the fusiform face area in the human (Kanwisher et al., 1997), although clearly more study is needed. The face patch O, whose correspondence to the macaque face system is not obvious, was a consistent feature of the fMRI data but was curiously absent in the ECoG results. Although the basis of this difference is unknown, it is interesting to speculate that it may be due to an inherent difference between the methods, with the BOLD signal better reflecting certain types of top-down modulation in the retinotopically organized visual areas (Maier et al., 2008). Direct comparison of this and other face patches with an activity-based estimation of the foveal extent did not suggest a clear retinotopic bias of face patches.

Future work will aim to gain information about potential homology of specific face patches in the different species. One important approach will be to compare the neuroanatomical projections of the different face patches in the marmoset with those of the macaque, which are presently being investigated (Grimaldi et al., 2013). Another avenue will be to compare aspects of face-selective single-unit responses. In the macaque, response properties, such as the sensitivity to face identity, viewing angle, and other attributes, differ among face patches (Freiwald and Tsao, 2010), and it is possible that analogous differences will exist among face patches in the marmoset. Finally, neural responses during free viewing paradigms can be used to infer area correspondences between species. One study applied this approach recently to study the regional similarity in the fMRI response time courses of macaques and humans watching the same video clips (Mantini et al., 2012). Although strict homology is notoriously difficult to establish, these types of comparative studies can shed light on which elements of face processing are conserved among primates, or more broadly among mammals, and which may have evolved more recently along the macaque or human lines (Leopold and Rhodes, 2010).

\section{The dorsal and ventral streams of face processing}

One similarity between our data and previous reports of faceselective responses in macaques and humans is the apparent division between dorsal and ventral face patches (Calder and Young, 2005; Pinsk et al., 2009; Yovel and Freiwald, 2013). The marmoset dorsal areas $\mathrm{PD}, \mathrm{MD}$, and $\mathrm{AD}$, which run along the shallow STS, may constitute a pathway for face processing that is distinct from the more ventral areas PV and MV. Although the coverage of our ECoG only permitted us to measure responses from four of these patches, the data were consistent with the possibility of two distinct streams. Specifically, the high-gamma responses to faces in the dorsal areas $\mathrm{PD}$ and $\mathrm{MD}$ were transient, 
which might imply that they receive a predominance of magnocellular input from a pathway leading through MT and FST. By contrast, PV and MV showed more sustained responses with a longer delay, which may indicate a larger contribution from the parvocellular visual pathway (Ferrera et al., 1992; Schmolesky et al., 1998). Anatomical tracer studies in the macaque are consistent with the view that multiple channels pass complex visual information into the temporal cortex, including to the faceselective regions (Kravitz et al., 2013). Such a division of labor in face processing may reflect different types of information extracted from faces. In the macaque, the more dorsal pathway into the STS is commonly associated with processing dynamic and animated stimuli (Oram and Perrett, 1994, 1996; Pitcher et al., 2011; Polosecki et al., 2013), whereas face-selective responses in the ventral visual pathway are more closely associated with visual recognition (Leopold et al., 2006; Freiwald and Tsao, 2010). Although further studies are needed, the apparently similar parallelism in the face patches of marmosets, macaques, and humans suggests that this feature of the ventral stream specialization for faces emerged before the split between Old and New World primates.

\section{The marmoset as a primate model for visual neuroscience}

Our findings of robust functional brain mapping in the awake, behaving marmoset underscores the great potential of this species as an experimental model for visual and systems neuroscience (Okano et al., 2012; Kishi et al., 2014; Solomon and Rosa, 2014). Previous work has shown that the basic layout of the marmoset brain, and in particular its visual cortex, shares primatespecific features with macaques (Rosa and Tweedale, 2005; Preuss, 2007; Cheong et al., 2013; Lui et al., 2013; McDonald et al., 2014; Yu and Rosa, 2014). Our study, together with recent work showing that marmosets can be trained to perform psychophysical tasks (Mitchell et al., 2014), suggests that this species can be used as a complementary species to the macaque to probe the neurobiology of cognition.

Importantly, the awake marmoset model opens the door to areas of investigation that are either impossible or impractical in the macaque. For example, it is possible to map the uninterrupted cortex along occipitotemporal and occipitoparietal pathways not only with fMRI and electrophysiological methods, but also with optical methods. At present, molecular and viral technologies developed in the mouse are increasingly available in the marmoset (Okada et al., 2013; Susaki et al., 2014; Watakabe et al., 2014), including the production of transgenic animals (Sasaki et al., 2009). Future experiments are likely to exploit these advances to study cognition, for example, by combining optogenetic circuit manipulation and large field optical imaging in the awake marmoset. The potential to functionally dissect circuits in this way can provide important new perspectives on the relationship between cortical activity and cognition, including aspects of highlevel visual social perception supported by similar circuitry in the human brain.

\section{References}

Asaad WF, Santhanam N, McClellan S, Freedman DJ (2013) Highperformance execution of psychophysical tasks with complex visual stimuli in MATLAB. J Neurophysiol 109:249-260. CrossRef Medline

Bell AH, Hadj-Bouziane F, Frihauf JB, Tootell RB, Ungerleider LG (2009) Object representations in the temporal cortex of monkeys and humans as revealed by functional magnetic resonance imaging. J Neurophysiol 101: 688-700. CrossRef Medline

Bentin S, Allison T, Puce A, Perez E, McCarthy G (1996) Electrophysiolog- ical studies of face perception in humans. J Cogn Neurosci 8:551-565. CrossRef Medline

Bock NA, Kocharyan A, Liu JV, Silva AC (2009) Visualizing the entire cortical myelination pattern in marmosets with magnetic resonance imaging. J Neurosci Methods 185:15-22. CrossRef Medline

Bock NA, Hashim E, Kocharyan A, Silva AC (2011) Visualizing myeloarchitecture with magnetic resonance imaging in primates. Ann N Y Acad Sci 1225 [Suppl 1]:E171-E181.

Calder AJ, Young AW (2005) Understanding the recognition of facial identity and facial expression. Nat Rev Neurosci 6:641-651. CrossRef Medline

Carlin JD, Calder AJ, Kriegeskorte N, Nili H, Rowe JB (2011) A head viewinvariant representation of gaze direction in anterior superior temporal sulcus. Curr Biol 21:1817-1821. CrossRef Medline

Cheong SK, Tailby C, Solomon SG, Martin PR (2013) Cortical-like receptive fields in the lateral geniculate nucleus of marmoset monkeys. J Neurosci 33:6864-6876. CrossRef Medline

Cox RW, Hyde JS (1997) Software tools for analysis and visualization of fMRI data. NMR Biomed 10:171-178. CrossRef Medline

Crone NE, Sinai A, Korzeniewska A (2006) High-frequency gamma oscillations and human brain mapping with electrocorticography. Prog Brain Res 159:275-295. CrossRef Medline

Delorme A, Makeig S (2004) EEGLAB: an open source toolbox for analysis of single-trial EEG dynamics including independent component analysis. J Neurosci Methods 134:9-21. CrossRef Medline

Ferrera VP, Nealey TA, Maunsell JH (1992) Mixed parvocellular and magnocellular geniculate signals in visual area V4. Nature 358:756-761. CrossRef Medline

Freeman WJ (2004) Origin, structure, and role of background EEG activity: 1. Analytic amplitude. Clin Neurophysiol 115:2077-2088. CrossRef Medline

Freiwald WA, Tsao DY (2010) Functional compartmentalization and viewpoint generalization within the macaque face-processing system. Science 330:845-851. CrossRef Medline

Grimaldi P, Saleem KS, Tsao DY (2013) Subcortical connections of the functionally-defined face patches in the macaque monkey. Society for Neuroscience, San Diego.

Gross CG (2008) Single neuron studies of inferior temporal cortex. Neuropsychologia 46:841-852. CrossRef Medline

Hasson U, Levy I, Behrmann M, Hendler T, Malach R (2002) Eccentricity bias as an organizing principle for human high-order object areas. Neuron 34:479-490. CrossRef Medline

Janssens T, Zhu Q, Popivanov ID, Vanduffel W (2014) Probabilistic and single-subject retinotopic maps reveal the topographic organization of face patches in the macaque cortex. J Neurosci 34:10156-10167. CrossRef Medline

Kanwisher N, McDermott J, Chun MM (1997) The fusiform face area: a module in human extrastriate cortex specialized for face perception. J Neurosci 17:4302-4311. Medline

Kendrick KM, Baldwin BA (1987) Cells in temporal cortex of conscious sheep can respond preferentially to the sight of faces. Science 236:448450. CrossRef Medline

Kishi N, Sato K, Sasaki E, Okano H (2014) Common marmoset as a new model animal for neuroscience research and genome editing technology. Dev Growth Differ 56:53-62. CrossRef Medline

Kravitz DJ, Saleem KS, Baker CI, Ungerleider LG, Mishkin M (2013) The ventral visual pathway: an expanded neural framework for the processing of object quality. Trends Cogn Sci 17:26-49. CrossRef Medline

Kriegeskorte N, Formisano E, Sorger B, Goebel R (2007) Individual faces elicit distinct response patterns in human anterior temporal cortex. Proc Natl Acad Sci U S A 104:20600-20605. CrossRef Medline

Ku SP, Tolias AS, Logothetis NK, Goense J (2011) fMRI of the faceprocessing network in the ventral temporal lobe of awake and anesthetized macaques. Neuron 70:352-362. CrossRef Medline

Lafer-Sousa R, Conway BR (2013) Parallel, multi-stage processing of colors, faces and shapes in macaque inferior temporal cortex. Nat Neurosci 16: 1870-1878. CrossRef Medline

Leopold DA, Rhodes G (2010) A comparative view of face perception. J Comp Psychol 124:233-251. CrossRef Medline

Leopold DA, Bondar IV, Giese MA (2006) Norm-based face encoding by single neurons in the monkey inferotemporal cortex. Nature 442:572575. CrossRef Medline

Liu JV, Hirano Y, Nascimento GC, Stefanovic B, Leopold DA, Silva AC 
(2013) fMRI in the awake marmoset: somatosensory-evoked responses, functional connectivity, and comparison with propofol anesthesia. Neuroimage 78:186-195. CrossRef Medline

Lui LL, Bourne JA, Rosa MG (2013) Relationship between size summation properties, contrast sensitivity and response latency in the dorsomedial and middle temporal areas of the primate extrastriate cortex. PLoS One 8:e68276. CrossRef Medline

Maier A, Wilke M, Aura C, Zhu C, Ye FQ, Leopold DA (2008) Divergence of fMRI and neural signals in V1 during perceptual suppression in the awake monkey. Nat Neurosci 11:1193-1200. CrossRef Medline

Mantini D, Hasson U, Betti V, Perrucci MG, Romani GL, Corbetta M, Orban GA, Vanduffel W (2012) Interspecies activity correlations reveal functional correspondence between monkey and human brain areas. Nat Methods 9:277-282. CrossRef Medline

McDonald JS, Clifford CW, Solomon SS, Chen SC, Solomon SG (2014) Integration and segregation of multiple motion signals by neurons in area MT of primate. J Neurophysiol 111:369-378. CrossRef Medline

Mitchell JF, Reynolds JH, Miller CT (2014) Active vision in marmosets: a model system for visual neuroscience. J Neurosci 34:1183-1194. CrossRef Medline

Moeller S, Freiwald WA, Tsao DY (2008) Patches with links: a unified system for processing faces in the macaque temporal lobe. Science 320:13551359. CrossRef Medline

Okada H, Ishibashi H, Hayashita-Kinoh H, Chiyo T, Nitahara-Kasahara Y, Baba Y, Watanabe S, Takeda S, Okada T (2013) Robust long-term transduction of common marmoset neuromuscular tissue with rAAV1 and rAAV9. Mol Ther Nucleic Acids 2:e95. CrossRef Medline

Okano H, Hikishima K, Iriki A, Sasaki E (2012) The common marmoset as a novel animal model system for biomedical and neuroscience research applications. Semin Fetal Neonatal Med 17:336-340. CrossRef Medline

Oram MW, Perrett DI (1994) Responses of anterior superior temporal polysensory (STPa) neurons to "biological motion" stimuli. J Cogn Neurosci 6:99-116. CrossRef Medline

Oram MW, Perrett DI (1996) Integration of form and motion in the anterior superior temporal polysensory area (STPa) of the macaque monkey. J Neurophysiol 76:109-129. Medline

Papoti D, Yen CC, Mackel JB, Merkle H, Silva AC (2013a) An embedded four channel receive-only RF coil array for fMRI experiments of the somatosensory pathway in conscious awake marmosets. NMR Biomed 26: 1395-1402. CrossRef Medline

Papoti D, Yen CC, Mackel JB, Merkle H, Silva AC (2013b) A whole-brain 8 channel receive-only embedded array for MRI and fMRI of conscious awake marmosets at 7T. Proc 21st Annual Meeting and Exhibit of the International Society for Magnetic Resonance and Medicine (ISMRM), Salt Lake City, April 20-26, 2013. p 2778.

Parr LA, Hecht E, Barks SK, Preuss TM, Votaw JR (2009) Face processing in the chimpanzee brain. Curr Biol 19:50-53. CrossRef Medline

Parvizi J, Jacques C, Foster BL, Witthoft N, Withoft N, Rangarajan V, Weiner KS, Grill-Spector K (2012) Electrical stimulation of human fusiform face-selective regions distorts face perception. J Neurosci 32:1491514920. CrossRef Medline

Paxinos G, Watson C, Petrides M, Rosa M, Tokuno H (2011) The marmoset brain in stereotaxic coordinates. Waltham, MA: Academic.

Peelen MV, Downing PE (2007) The neural basis of visual body perception. Nat Rev Neurosci 8:636-648. CrossRef Medline

Pinsk MA, DeSimone K, Moore T, Gross CG, Kastner S (2005) Representations of faces and body parts in macaque temporal cortex: a functional MRI study. Proc Natl Acad Sci U S A 102:6996-7001. CrossRef Medline

Pinsk MA, Arcaro M, Weiner KS, Kalkus JF, Inati SJ, Gross CG, Kastner S (2009) Neural representations of faces and body parts in macaque and human cortex: a comparative FMRI study. J Neurophysiol 101:25812600. CrossRef Medline

Pitcher D, Dilks DD, Saxe RR, Triantafyllou C, Kanwisher N (2011) Differential selectivity for dynamic versus static information in face-selective cortical regions. Neuroimage 56:2356-2363. CrossRef Medline

Polosecki P, Moeller S, Schweers N, Romanski LM, Tsao DY, Freiwald WA (2013) Faces in motion: selectivity of macaque and human face processing areas for dynamic stimuli. J Neurosci 33:11768-11773. CrossRef Medline
Preuss TM (2007) Evolutionary specializations of primate brain systems. In: Primate origins: adaptations and evolution (Ravosa MJ, Dagasto M, eds), pp 625-675. New York: Springer.

Puce A, Allison T, Asgari M, Gore JC, McCarthy G (1996) Differential sensitivity of human visual cortex to faces, letterstrings, and textures: a functional magnetic resonance imaging study. J Neurosci 16:5205-5215. Medline

Puce A, Allison T, Bentin S, Gore JC, McCarthy G (1998) Temporal cortex activation in humans viewing eye and mouth movements. J Neurosci 18:2188-2199. Medline

Ray S, Maunsell JH (2011) Different origins of gamma rhythm and highgamma activity in macaque visual cortex. PLoS Biol 9:e1000610. CrossRef Medline

Rosa MG, Tweedale R (2005) Brain maps, great and small: lessons from comparative studies of primate visual cortical organization. Philos Trans R Soc Lond B Biol Sci 360:665-691. CrossRef Medline

Sasaki E, Suemizu H, Shimada A, Hanazawa K, Oiwa R, Kamioka M, Tomioka I, Sotomaru Y, Hirakawa R, Eto T, Shiozawa S, Maeda T, Ito M, Ito R, Kito C, Yagihashi C, Kawai K, Miyoshi H, Tanioka Y, Tamaoki N, et al. (2009) Generation of transgenic non-human primates with germline transmission. Nature 459:523-527. CrossRef Medline

Schmolesky MT, Wang Y, Hanes DP, Thompson KG, Leutgeb S, Schall JD, Leventhal AG (1998) Signal timing across the macaque visual system. J Neurophysiol 79:3272-3278. Medline

Silva AC, Liu JV, Hirano Y, Leoni RF, Merkle H, Mackel JB, Zhang XF, Nascimento GC, Stefanovic B (2011) Longitudinal functional magnetic resonance imaging in animal models. Methods Mol Biol 711:281-302. CrossRef Medline

Solomon SG, Rosa MG (2014) A simpler primate brain: the visual system of the marmoset monkey. Front Neural Circuits 8:96. CrossRef Medline

Susaki EA, Tainaka K, Perrin D, Kishino F, Tawara T, Watanabe TM, Yokoyama C, Onoe H, Eguchi M, Yamaguchi S, Abe T, Kiyonari H, Shimizu Y, Miyawaki A, Yokota H, Ueda HR (2014) Whole-brain imaging with single-cell resolution using chemical cocktails and computational analysis. Cell 157:726-739. CrossRef Medline

Tsao DY, Livingstone MS (2008) Mechanisms of face perception. Annu Rev Neurosci 31:411-437. CrossRef Medline

Tsao DY, Freiwald WA, Knutsen TA, Mandeville JB, Tootell RB (2003) Faces and objects in macaque cerebral cortex. Nat Neurosci 6:989-995. CrossRef Medline

Tsao DY, Freiwald WA, Tootell RB, Livingstone MS (2006) A cortical region consisting entirely of face-selective cells. Science 311:670-674. CrossRef Medline

Tsao DY, Moeller S, Freiwald WA (2008) Comparing face patch systems in macaques and humans. Proc Natl Acad Sci U S A 105:19514-19519. CrossRef Medline

Van Essen DC (2012) Cortical cartography and Caret software. Neuroimage 62:757-764. CrossRef Medline

Watakabe A, Ohtsuka M, Kinoshita M, Takaji M, Isa K, Mizukami H, Ozawa $\mathrm{K}$, Isa T, Yamamori T (2014) Comparative analyses of adeno-associated viral vector serotypes 1, 2, 5, 8 and 9 in marmoset, mouse and macaque cerebral cortex. Neurosci Res. Advance online publication. Retrieved Sep 18, 2014. doi: 10.1016/j.neures.2014.09.002. CrossRef Medline

Weiner KS, Grill-Spector K (2013) Neural representations of faces and limbs neighbor in human high-level visual cortex: evidence for a new organization principle. Psychol Res 77:74-97. CrossRef Medline

Yovel G, Freiwald WA (2013) Face recognition systems in monkey and human: are they the same thing? F1000Prime Rep 5:10. CrossRef Medline

Yu HH, Rosa MG (2014) Uniformity and diversity of response properties of neurons in the primary visual cortex: selectivity for orientation, direction of motion, and stimulus size from center to far periphery. Vis Neurosci 31:85-98. CrossRef Medline

Yushkevich PA, Piven J, Hazlett HC, Smith RG, Ho S, Gee JC, Gerig G (2006) User-guided $3 \mathrm{D}$ active contour segmentation of anatomical structures: significantly improved efficiency and reliability. Neuroimage 31:11161128. CrossRef Medline

Zangenehpour S, Chaudhuri A (2005) Patchy organization and asymmetric distribution of the neural correlates of face processing in monkey inferotemporal cortex. Curr Biol 15:993-1005. CrossRef Medline 